Please do not remove this page

RMIT

UNIVERSITY

\title{
Active bioparticle manipulation in microfluidic systems
}

Ali, Mohd; Ostrikov, Kostya; Khalid, Fararishah; Majlis, Burhanuddin; Kayani, Aminuddin https://researchrepository.rmit.edu.au/esploro/outputs/9921860783501341/filesAndLinks?institution=61 RMIT_INST\&index=null

Ali, M., Ostrikov, K., Khalid, F., Majlis, B., \& Kayani, A. (2016). Active bioparticle manipulation in microfluidic systems. RSC Advances, 6(114), 113066-113094. https://doi.org/10.1039/C6RA20080J

Document Version: Accepted Manuscript

Published Version: https://doi.org/10.1039/C6RA20080J

Repository homepage: https://researchrepository.rmit.edu.au

(C) The Royal Society of Chemistry 2016

Downloaded On 2023/04/26 14:53:04 +1000

Please do not remove this page 


\section{Active Bioparticle Manipulation in Microfluidic Systems}

Received 00th January 20xx Accepted 00th January 20xx

\begin{abstract}
Mohd Anuar Md Ali ${ }^{\mathrm{a}}$, Kostya (Ken) Ostrikov ${ }^{\mathrm{bc}}$, Fararishah Abdul Khalid ${ }^{\mathrm{d}}$, Burhanuddin Y. Majlis and Aminuddin A. Kayani*aef

The motion of bioparticles in a microfluidic environment can be actively controlled using several tuneable mechanisms, including hydrodynamic, electrophoresis, dielectrophoresis, magnetophoresis, acoustophoresis, thermophoresis and optical forces. These mechanisms are applied to obtain desired bioparticle motions which are important in facilitating different biological processes. In this work, we review the fundamentals, features and applications of these tuneable mechanisms for the manipulation of bioparticles such as proteins, nucleic acids, viruses, bacteria, stem cells, cancer and tumor cells, blood cells and multicellular organisms in microfluidic systems. We focus on applications that can realize biomedical devices potentially suitable in diagnostic, therapeutic or analytical applications. Future perspectives of microfluidic systems incorporating active bioparticle manipulation mechanisms are included.
\end{abstract}

\section{Introduction}

Advancement of biomedical studies has resulted in miniaturization of biomedical platforms. The main considerations in establishing successful miniaturization is to create a controlled environment which promotes predictive micro/nano particle behaviors, reduction in sample quantity that allows characterization of scarce materials such as patient-derived samples ${ }^{1}$ and at the clinical level, to try and reduce the time and cost related to diagnostic and therapeutic treatments. ${ }^{1}$ Scaling down conventional clinical procedures into a microscale environment has been achieved by imitating macroscale processes and achieving required localization properties by using different externally applied forces. ${ }^{2}$

Microfluidic systems is a platform for researchers to create a microscale environment and allows them to explore the behaviors and responses of micro/nano particles towards these applied forces. In the context of establishing biomedical devices, microfluidics is highly relevant as majority of biological micro/nano particles (bioparticles) exist or are suspended in a liquid environment such as blood, urine, sweat and other biological fluids. ${ }^{3}$ In microfluidics, manipulation of bioparticles

\footnotetext{
a. Institute of Microengineering and Nanoelectronics, Universiti Kebangsaan Malaysia, Bangi, Selangor 43600, Malaysia.Email: burhan@ukm.edu.my b. School of Chemistry, Physics, and Mechanical Engineering, Queensland University of Technology, Brisbane QLD 4000, Australia.Email: kostya.ostrikov@qut.edu.au

c. CSIRO-QUT Joint Sustainable Materials and Devices Laboratory, P. O. Box 218, Lindfield NSW 2070, Australia.

d. Faculty of Technology Management and Technopreneurship, Universiti Teknikal Malaysia Melaka, Melaka 75300, Malaysia.Email: fararishah@utem.edu.my

e. Center for Advanced Materials and Green Technology, Multimedia University,

Melaka, Melaka 75450, Malaysia.Email: aminuddin.kayani@mmu.edu.my

f. School of Engineering, RMIT University, VIC 3001, Australia.

* Corresponding author

+ Electronic Supplementary Information (ESI) available: See

DOI: $x x . x x x x / x x x x x x x x x x$
}

can be achieved by employing active manipulation forces.

Active manipulation of bioparticles is a process to control particle displacement and motional trajectories in a highly predictable and consistent fashion, ${ }^{4}$ by introducing external flow or pressure control devices and structural geometries which induce optimized hydrodynamic forces, 5,6 or by embedding external systems to exert forces such as electrophoretic, ${ }^{7,8} \quad$ dielectrophoretic, ${ }^{8-10}$ magnetophoretic, ${ }^{4,11-14} \quad$ acoustophoretic, ${ }^{15,16}$ thermophoretic ${ }^{17,18}$ and optical gradient forces or optical tweezing. ${ }^{19-21}$ Conversely, passive manipulation forces such as Van der Waals attraction, ${ }^{22}$ self-assembly, ${ }^{23}$ Brownian motion ${ }^{24}$ and charged dipole interaction ${ }^{25}$ are random and unpredictable and thus do not constitute the focus of this review. Engaging active manipulation forces creates unique opportunities for controlling, sorting, trapping and delivering bioparticles, which can potentially be translated into commercialized biomedical devices. Further, the laminar flow in microfluidic environments allows precise analysis of bioparticle responses to external stimuli at the cellular and molecular levels as there are fewer disturbances caused by erratic hydrodynamic events. ${ }^{26}$

Our aim is to provide a concise review of active manipulation forces for manipulate bioparticles. Several related reviews have been published. A number of them focused on the manipulation of specific bioparticles such as stem cells, ${ }^{7,8}$ cancer cells, $, 27,28$ nucleic acid 29,30 and tumor cells ${ }^{31,32}$ have been published. Some review papers were oriented on the discussion of certain biomedical protocols and procedures such as cell electrofusion, ${ }^{33-35}$ blood fractionation, ${ }^{4}$ analytical detection, ${ }^{36}$ mixing and microfluidic reactors for the production of biomedical nanomaterials, ${ }^{41}$ Raman spectroscopy for biological analysis ${ }^{37}$ and drug discovery or delivery. ${ }^{43}$ Others focused on particular active manipulation forces and discussed the applications such as inertial focusing 
or hydrodynamic forces, ${ }^{4,39-41}$ electrical forces including electrophoretic ${ }^{42,43}$ and dielectrophoretic, ${ }^{44}$ magnetophoretic ${ }^{45-47}$ and acoustophoretic forces. ${ }^{48}$

We divided this review to three sections. First, we overviewed bioparticle manipulation forces including hydrodynamic, ${ }^{48}$ electrophoretic, ${ }^{49}$ dielectrophoretic, ${ }^{49}$ magnetic, ${ }^{50}$ acoustic, $^{55}$ thermal $^{51}$ and optical ${ }^{4,11-14}$ forces in microfluidics. In the subsequent section, we review microfluidic platforms incorporating bioparticle manipulation based on the active manipulation forces. We conclude our review with future perspectives of this multi-disciplinary field. A brief overview of the features and functions of bioparticles generally used in microfluidic systems is provided in Table S1 of the Electronic Supplementary Information (ESI).

\section{Bioparticle Active Manipulation Forces}

In this section, we review fundamentals of active manipulation forces for controlling trajectories and locations of bioparticles in microfluidic systems, including: (1) hydrodynamic; (2) electrophoretic; (3) dielectrophoretic; (4) magnetophoretic; (5) acoustophoretic; (6) thermophoretic; forces and (7) optical tweezing.

\subsection{Hydrodynamic}

Hydrodynamic (HYD) forces originate from liquid motion. ${ }^{52-54}$ HYD forces can induce precision particle motions under laminar flow in microfluidic systems and may separate bioparticles according to their size and mass. 55

The flow regime, whether laminar or turbulent, is determined by the Reynolds number, $R e_{d}$, which is defined as the ratio of inertial to viscous forces, as shown in eqn (1), where $\rho_{m}$ is the medium density, $v_{f}$ is the average velocity of the medium, $L$ is the microfluidic channel's equivalent diameter, and $\mu_{m}$ is the dynamic viscosity of the medium. ${ }^{4,6}$ Laminar flow exhibits when $R e_{d}$ is less than 1000.

$$
R e_{d}=\frac{\rho_{m} v_{f} L}{\mu_{m}}
$$

During movement in a microfluidic system, bioparticles experience two dominant forces, namely the viscous drag force and the inertial lift force. Viscous drag force, $F_{D}$, which given in eqn (2), propels the particle along the flow streamlines according to Stokes law. The inertial lift force, $F_{L}$, given in eqn (3), on the other hand, is the net lift force between the wall-induced lift force and the shear-induced lift force, in the direction crossing the streamlines. $F_{L}$ causes the particles to converge to an equilibrium position between the microfluidic channel centerline and sidewall. In eqn (2) and eqn (3), $a$ is particle radius, $U_{p}$ is relative velocity between the particle and the surrounding medium and $C_{L}$ is lift coefficient that depends on fluid density that surrounds the bioparticle. ${ }^{56}$

$$
\begin{aligned}
& F_{D}=6 \pi \mu_{m} a U_{p} \\
& F_{L}=\frac{4 \rho_{m} C_{L} v_{f}^{2} a^{4}}{3 \pi \mu_{m} L^{2}}
\end{aligned}
$$

For liquid that flows in a curved microchannel, the flow profile is influenced by secondary flow drag force, which manifests as a pair of counter-rotating vortices positioned symmetrically above and below the channel mid-plane. ${ }^{57}$ The rotating flow is characterized by the Dean number, $\kappa$, given in eqn (4), where $\delta=d / R$ and $R$ is the radius of the flow path radius curvature. A detailed discussion on the interplay between axial flow and secondary flow is included in the ESI.

$$
\kappa=\delta^{0.5} R e_{d}
$$

The geometrical structure of the microfluidic channel is one of the factors contributing to bioparticle motion in liquid. Other factors include the existence of externally driven pressures or flow control devices. Typical geometries for microchannels include straight, ${ }^{58}$ curved, ${ }^{59}$ spiral, ${ }^{60}$ asymmetric curves $^{61}$ and contraction-expansion ${ }^{26}$ channels. Each geometry can impose different magnitude and change of wall-induced lift force, shear-induced lift force and secondary flow drag force along the channel, giving the ability to conduct desired manipulation. ${ }^{62}$ An example of the manipulation of bioparticles using the HYD force is depicted in Fig. 1a.

\subsection{Electrophoresis}

Electrophoresis is the motion of charged particles in a fluid under the influence of an electric field. ${ }^{63}$ Electrophoretic (EP) force has the advantage of low sample and buffer requirement, high separation efficiency, versatility, sensitivity and short analysis time. It has limitations where it requires the suspending medium to be conductive and usually the availability of the compound of interest is limited by the complexity of the purification procedure and the cost of synthesis. Electrophoresis has been widely used for DNA fingerprinting, ${ }^{64}$ drug analysis ${ }^{15,16}$ and protein characterization. ${ }^{65}$

Electrophoresis is generated by suspending particles in an ionic solution with a pair of electrodes connected to a direct current (DC) power source is placed. When the electrical field is applied, the EP force, $F_{E P}$ is generated which move the charged particles to the electrode with the opposite charge polarity. The induced motion depends on the polarity and magnitude of the net electrical charge of the particle. The net force depends on the combined effect with the friction force, $F_{F R}$, and the electrophoretic retardation force, $F_{R E T}$. Friction force $F_{F R}$ is the viscous force, which depends on the suspending medium viscosity and the particle size. The EP retardation force, $F_{R E T}$ is the force that is exerted on the diffused cloud of ions with opposite charge polarity to the particle that surrounds it, known as the Debye layer which causes a fluid flow having a direction that is opposite to the electrophoretic force. This results in a frictional drag that retards the electrophoretically induced motion. ${ }^{66}$

Electrophoretic mobility, $\mu_{E P}$, is the measure of charged particle mobility under the electric field. When a particle is suspended in a low Reynolds number medium with a moderate electric field, $E$ applied, the EP mobility, $\mu_{E P}$, experienced by the particle is shown in eqn (5), where $v$ is the velocity of suspended particle. 


$$
\mu_{E P}=\frac{v}{E}
$$

Advanced electrophoretic mobility theories developed by Smoluchowski67 and Hückel are described in the ESI. An example of manipulation of bioparticles using the EP force is depicted in Fig. $1 \mathrm{~b}$.

\subsection{Dielectrophoresis}

Dielectrophoresis is the motion of particles induced by a spatially non-uniform electric field. ${ }^{68}$ Particles are temporarily polarized, establishing dipoles which induce unequal Columbic forces causing the particles to move. ${ }^{69}$ The dielectrophoretic (DEP) force is highly selective, label-free, quick and low-cost in fabrication. ${ }^{9,48-50}$ Disadvantages associated with DEP manipulation are related to controlling bioparticles in the nanoscale regime and the risk of bioparticle damage due to exposure to strong electric fields. ${ }^{70}$ Dielectrophoresis has been successfully used for cancer cell detection, leukaemia cell separation and fractionation of cells and proteins. ${ }^{71}$

The DEP force, $F_{D E P}$, which is valid for a stationary alternative-current (AC) field is given in eqn (6), where $E$ is the electric field, $\varepsilon_{m}$ is the permittivity of the suspending medium, $a$ is particle radius, and $f_{C M}$ is Clausius-Mossotti (CM) factor. The $f_{C M}$ describes the relationship between dielectric constants of two different media and for a spherical particle, $f_{C M}$ is given as per eqn (7), where $\varepsilon$ is the complex permittivity, and subscripts " $p$ " and " $m$ " stand for the particle and the medium, respectively.

$$
\begin{gathered}
F_{D E P}=2 \pi a^{3} \varepsilon_{m} \operatorname{Re}\left[f_{C M}\right] \nabla|E|^{2} \\
f_{C M}=\frac{\varepsilon_{p}^{*}-\varepsilon_{m}^{*}}{\varepsilon_{p}^{*}+2 \varepsilon_{m}^{*}}
\end{gathered}
$$

The DEP force is proportional to particle volume, and is highly dependent on the electrical properties of the particle and medium, and the frequency of the field. The polarity of the DEP force depends on the sign of the $f_{C M} .{ }^{72,73}$ If $f_{C M}$ is positive (pDEP), bioparticles will be attracted to the region of high electric field gradients. Conversely if $f_{C M}$ is negative (nDEP), bioparticles will be repelled from those regions.

For an AC field that has spatial variation in space, which is applied in travelling wave DEP (twDEP) and electrorotation (ER) manipulation, the DEP force is given by eqn (8), where, $\operatorname{Re}\left[f_{C M}\right]$ is the real part of $f_{C M}, \operatorname{Im}\left[f_{C M}\right]$ is the imaginary part, $\varphi$ is the phase of the AC-field, and subscript $i$ refers to each component of the electric field and the phase gradient. The last term in the parenthesis is the tensor notation, which refers to the summation of the vector components. ${ }^{74}$

$$
F_{D E P}=2 \pi a^{3} \varepsilon_{m} \operatorname{Re}\left[f_{C M}\right] \nabla|E|^{2}+2 \pi a^{3} \varepsilon_{m} \operatorname{Im}\left[f_{C M}\right] \times\left(\left|E_{i}\right|^{2} \nabla \varphi_{i}\right)
$$

The twDEP is typically generated by applying $90^{\circ}$ phaseshifted voltages $\left(0^{\circ}, 90^{\circ}, 180^{\circ}\right.$, and $270^{\circ}$ phase-shifted) on a planar parallel microelectrode array. In twDEP, a travelling wave of electrostatic potential is generated that can suspend a lossy dielectric sphere vertically while simultaneously propelling it along the array. The ER is generated by quadrupole $\left(90^{\circ}\right.$ phase shifted voltages) electrodes. When the electrodes are excited with this multiphase AC voltage, a rotating electric field is generated. Further details regarding twDEP and ER are provided in the ESI.

Bioparticles are typically multilayered due to presence of multilayer membranes. In this case, the particles' permittivity to be used for calculating the $f_{C M}$ is the overall permittivity of the bioparticle, taking into account the permittivity of all layers, which is further described in the ESI.

Transition between the pDEP and nDEP responses occur when the polarization of the particle and the suspending medium are the same. This occurs at a certain frequency, called the crossover frequency, $f_{x o}$. For the case of a spherical particle, $f_{x o}$ is given in eqn (9), where $\sigma_{m}$ is the conductivity of the surrounding medium, $a$ is the particle radius and $C_{m}$ is the capacitance of the bioparticle plasma membrane, which per unit area is typically in the range of $10^{-2}\left(\mathrm{Fm}^{-2}\right) .{ }^{72}$

$$
f_{x o}=\frac{\sqrt{2} \sigma_{m}}{2 \pi a c_{m}}
$$

A schematic diagram explaining the manipulation of bioparticles using the DEP force is provided in Fig. 1c.

\subsection{Magnetophoresis}

Magnetophoresis is the motion of particles due to the exposure to a non-uniform magnetic field. The target bioparticle is magnetized during this exposure and is either pushed toward the regions of high magnetic flux density or away from. The suspending medium is generally a magnetic or immuno-magnetic liquid such as iron oxide, saline, or phosphate buffered saline (PBS). ${ }^{75,76}$ The magnetic field can be generated by a permanent magnets or an electromagnetic coil. Magnetophoresis is preferred for bioparticle manipulation, as magnetic particles can bind to targeted bioparticles. Additionally, the magnetophoretic (MAG) force is non-invasive, does not cause bioparticle latency and can induce angular rotation and positioning. ${ }^{77,78}$ However, bioparticles may suffer a hysteresis effect, which causes agglomeration after the magnetic stimuli is removed. ${ }^{79}$

The MAG force, $F_{M A G}$, experienced by a particle is governed by eqn (10), where $\chi_{p}$ and $\chi_{m}$ are the magnetic susceptibility of the particle and the medium, respectively, $V_{p}$ is the volume of the particle, $B$ is the magnetic flux density, and $\mu_{0}$ is the permeability of free space..$^{80}$

$$
F_{M A G}=\frac{\left(\chi_{p}-\chi_{m}\right) V_{p}}{\mu_{0}}(B \cdot \nabla) B
$$

The direction of the particle motion, whether pushed to high magnetic flux density or repelled from it, is determined by the magnetic susceptibility difference between the particle and the suspending medium, $\chi_{p}-\chi_{m}$. When the magnetic susceptibility difference is positive $\left(\chi_{p}-\chi_{m}>0\right)$, the suspended particles experience a positive magnetophoretic force (pMAG), and are pushed to areas where magnetic field flux gradient is maximum. In contrast, when the magnetic susceptibility difference is negative, $\left(\chi_{p}-\chi_{m}<0\right)$ the suspended particles experience a negative magnetophoretic force (nMAG), and are pushed to areas where magnetic field flux gradient is minimum. 
Typical practice of bioparticle manipulation using magnetophoresis has been either by using paramagnetic microparticles, known as immuno-magnetic bioparticle manipulation, or by using paramagnetic or ferro-fluid suspending media, known as diamagnetic bioparticle manipulation. ${ }^{20}$ Magnetic particles can be classified into three categories, such as ferromagnetic, paramagnetic and diamagnetic, which are elaborated in the ESI.

In immuno-magnetic bioparticle manipulation, paramagnetic microparticles, such as iron oxide micro/nano particles and streptavidin paramagnetic particles with high susceptibility compared to suspending medium are used. In this method, targeted bioparticles are attached to paramagnetic particles through antibodies, which have binding affinity to bioparticles. When exposed to a magnetic field, the microparticles attached to bioparticles can be manipulated. Conversely, in diamagnetic bioparticle manipulation, a suspending medium with high magnetic susceptibility compared to the targeted bioparticle is used. In this method, the magnetic field manipulates the suspending medium rather than the bioparticles themselves.

Magnetic particles have been widely used for in vivo drug delivery applications involving cellular therapy, tissue repair, hyperthermia and magnetofection. These particles have high magnetic susceptibility that allow a targeted delivery with particle localization in specific areas. ${ }^{81}$ An example of bioparticle manipulation using the MAG force is depicted in Fig. 1d.

\subsection{Acoustophoresis}

Acoustophoresis is the movement of bioparticles when exposed to a surface acoustic wave (SAW) radiation pressure, either in travelling surface acoustic wave (TSAW) or standing surface acoustic wave (SSAW) mode. ${ }^{46}$ A TSAW occurs when a SAW is propagating from interdigitated transducer (IDT) electrodes. In the case of a SSAW, two TSAW constructively interfere and form a standing or stationary SAW. TSAW is generated by a single IDT electrode, while the SSAW can be generated either by a pair of IDT electrodes or a combination of a single IDT and wave reflectors. ${ }^{82,83}$ In TSAW acoustophoresis, bioparticles move together with the propagation of the SAW, while in a SSAW acoustophoresis, bioparticles are pushed toward the SAW pressure node or the pressure antinode.

The acoustophoretic (ACT) force is non-invasive and versatile, requires simple fabrication procedures, and is convenient to integrate with lab-on-chip (LOC) microfluidic devices. ${ }^{84}$ Acoustophoresis faces the challenge of isolating and separating rich combinations of bioparticles such as numerous types of bioparticles residing in a microfluidic suspension. 85 Acoustophoresis has been applied to numerous biomedical applications, such as plasma protein removal and isolation of low-molecular-weight compounds from red blood cells (RBCs), ${ }^{62}$ separation of heterogeneous cell mixtures in continuous flow, ${ }^{86}$ separation of lymphocyte subsets from peripheral blood progenitor cells, 61 and trapping and aggregation of lung cancer cells. ${ }^{58}$
The magnitude of the ACT force, $F_{a x}$, experienced by a particle is governed by eqn (11),87 where, $E_{a c}$ is the acoustic energy density, $a$ is the particle radius and $x$ is the distance from pressure antinode in the wave propagation axis, $k$ is the wave number $\left(2 \pi f / c_{0}\right)$ and $\varphi$ is the acoustic contrast factor.

$$
F_{a x}=4 \pi a^{3} E_{a c} k \sin (2 k x) \varphi
$$

The direction of particle movement, whether pushed towards the pressure node or pressure antinode, is determined by the sign of the acoustic contrast factor, $\varphi$, which is governed by eqn (12), where $\rho_{p}$ and $\rho_{o}$ are density of the particle and medium, respectively, $c_{p}$ and $c_{0}$ are the speed of sound within the particle and medium, respectively.

$$
\varphi=\frac{\rho_{p}+\frac{2}{3}\left(\rho_{p}-\rho_{0}\right)}{2 \rho_{p}+\rho_{0}}-\frac{1}{3} \frac{\rho_{0} c_{0}^{2}}{\rho_{p} c_{p}^{2}}
$$

When the acoustic contrast factor is positive $(\varphi>0)$, particles experience positive acoustophoresis (pACT), and are pushed towards the pressure node. In contrast, when the acoustic contrast factor is negative $(\varphi<0)$, particles experience negative acoustophoresis (nACT), and are pushed towards the pressure antinode. A schematic of bioparticle manipulation using the ACT force is depicted in Fig. 1e.

\subsection{Thermophoresis}

Thermophoresis is the motion of particles driven by thermal gradients in the suspending medium. Thermal gradients are usually generated locally by absorption of infrared (IR) laser. The thermal gradients cause the particles move by diffusion, either towards higher or lower temperature medium. ${ }^{88}$

Thermophoretic (THM) manipulation is favoured due to it being label-free, immobilization-free and applicable for sub-cell manipulation. ${ }^{89}$ However, THM has limitations, including difficulty in transporting low concentrations of bioparticles and the system must be free from convective flows. 90

Liquid flow density, $J$ driven by the THM field, is given in eqn (13), where, $D$ is the diffusion coefficient, $c$ is the concentration, $T$ is temperature, and $S_{T}$ is the Soret coefficient, defined as the ratio of the thermal diffusion coefficient, $D_{T}$, over the diffusion coefficient, $D$, shown in eqn (14).

$$
\begin{gathered}
J=D\left[\nabla c+S_{T} c(1-c) \nabla T\right] \\
S_{T}=\frac{D_{T}}{D}
\end{gathered}
$$

Steady state concentration changes for a given spatial temperature difference, $\Delta T$ is given by eqn (15), where, $c_{\text {hot }}$ is the molecule concentration in the hot area, while $c_{\text {cold }}$ is in the cold area.

$$
\frac{c_{\text {hot }}}{c_{\text {cold }}}=\exp \left(-S_{T} \Delta T\right)
$$

The representation of molecular diffusion driven by the THM force is depicted in Fig. $1 \mathrm{f}$ below.

\subsection{Optical tweezing}

The process of manipulating bioparticles using optical forces is commonly known as optical tweezing (OPT), which refers to using light radiation pressure to displace bioparticles. ${ }^{91}$ OPT is 
applied to control bioparticles without mechanical contact and is classified as a label-free method. ${ }^{47}$ OPT manipulation has the advantage of high precision motion and immobilization. However, it has the disadvantage of being confined to handle low volume of samples and poses the risk of damaging bioparticles due to over-exposure towards optical electromagnetic fields and over-heating of the cells. ${ }^{92}$ OPT manipulation has been used in alignment of cell's nucleus, trapping of bacterial cells, 3D micro patterning of biological structures and single-molecule studies of DNA. ${ }^{93}$

Optical fields emitted by a light source, causes scattering and gradient forces, which affect the motion of the particle in the propagation axis. Scattering forces, $F_{\text {scat }}$ work in the direction of propagation, where the particle is pushed away from the light source. Gradient forces, $F_{\text {grad }}$, on the other hand, work in the direction of the OPT field gradient, resulting in the particle being attracted to the region of peak spatial light intensity.

There are two fundamental explanations for OPT manipulation, known as the Mie and Rayleigh regime explanations. Both are derived based on the dimension of particle size with respect to optical wavelength. Details of this are provided in the ESI.

Particles can be considered as an infinitesimally induced point dipoles that interact with the light field resulting from polarization in homogeneous electrical field. ${ }^{94}$ In a homogeneous electric field $E$, the induced dipole moment, $p_{\text {dipole, }}$ by polarization is given in eqn (16), where, $n_{1}$ is refractive index of suspending medium, $n_{2}$ is refractive index of the particle, $a$ is radius of the particle, $\varepsilon_{0}$ is permittivity in vacuum and $m$ is the index contrast ratio, where $m=n_{2} / n_{1}$.

$$
p_{\text {dipole }}=4 \pi n_{1}^{2} \varepsilon_{0} a^{3}\left(\frac{m^{2}-1}{m^{2}+2}\right) E
$$

The magnitudes of the scattering force, $F_{\text {scat }}$, and gradient force, $F_{\text {grad }}$, based on point dipole interaction with light field method are given in eqn (17) and eqn (18), where, $I$ is light intensity, $c$ is the speed of light, $k$ is the wave number $(k=2 \pi / \lambda)$ and $\lambda$ is the wavelength. ${ }^{95}$

$$
\begin{aligned}
& F_{\text {scat }}=\frac{8 \pi n_{1} k^{4} a^{6}}{3 c}\left(\frac{m^{2}-1}{m^{2}+2}\right) I \\
& F_{\text {grad }}=\frac{2 \pi n_{1} a^{3}}{c}\left(\frac{m^{2}-1}{m^{2}+2}\right) \nabla I
\end{aligned}
$$

Trapping is achieved at the highest intensity axis when $F_{\text {grad }}>F_{\text {scat }}$. OPT manipulation works by light emission through a high numerical aperture number (NA) microscope objective (MO), which focuses light tightly which results in a force along the highest intensity axis, but in the reverse direction, which causes the bioparticle to be immobilized. ${ }^{96}$ Fig. $1 \mathrm{~g}$ shows a pictorial example of bioparticle manipulation using the OPT force.

\section{Active Manipulation Platforms Using Bioparticles}

In this section, we overview the bioparticle manipulation platforms focusing on bioparticle behaviors and the application of active manipulation forces in microfluidic systems.

\subsection{Model organisms}

Model organisms are important bioparticles in biomedical studies. They comprise of unicellular and multicellular organisms. One of the most widely used unicellular microorganisms are yeast, because of their ease of genetic manipulation, short generation time and conservation of eukaryotic physiology features. ${ }^{97}$

Yeast is an important model in biomedicine for studying cellular processes such as cell cycle, cell division, metabolism, DNA replication and recombination. ${ }^{51}$ In term of microfluidics, yeast cells have been widely used for proof of concept studies, to demonstrate the system capability in sorting, trapping and drug stimulation of cells. ${ }^{98}$ Potential application of yeast cells are the development of diagnostic and therapeutic tools, drugs discovery research for cancer treatment related to cell cycle interfering and the study on genes turning on or off in normal developmental processes and disease occurrence. ${ }^{99}$ Yeast manipulation in microfluidics has been demonstrated with different forces including the HYD, ${ }^{59}$ DEP, $46,82,84,100$ MAG ${ }^{62}$ and ACT. 86

Warkiani et al.59 developed a microfiltration and fractionation microfluidic system using the HYD force by a curved channel with trapezoidal cross-section shape which induces high Dean vortices. The vortices force smaller particles towards the outer wall while larger particles towards the inner wall. They demonstrated the filtration and fractionation using yeast. Zhu et al. 82 demonstrated separation of yeast from a mixture with polystyrene (PS) microspheres using a DEP platform which was fabricated using screen printing technology. The yeast experienced PDEP force trapping them along the electrodes, while PS microspheres experienced nDEP repelling them along the channel under the HYD force. Burgarella et al. 100 demonstrated the sorting of yeast and sheep blood cells from an aqueous solution using dielectrophoresis. Yeast experienced pDEP while blood cells experience $\mathrm{nDEP}$ at $1 \mathrm{MHz}$ frequency. The platform can be used for dielectric analysis of cells, by measuring the distribution of the linear velocity and rotational velocity. The measurement provides a method for experimentally estimating the $f_{C M}$.

Jaramillo et al. ${ }^{84}$ developed a 3D carbon DEP platform used for rapid sample purification from contaminants for subsequent polymerase chain reaction (PCR) processes. They demonstrated yeast purification using this platform and showed that it can significantly improve the sensitivity of PCR analysis. PCR is a process used to amplify a single copy or a few strands of DNA generating larger number of copies of a particular DNA sequence. ${ }^{101}$ Van Den Driesche et al. ${ }^{46}$ used twDEP to perform separation of levitated grown cells. Parallel electrodes are positioned along a microfluidic channel to generate the twDEP force onto selected cells perpendicular to the pressure driven flow. They separated viable yeast from a cell culture mix containing culture debris, non-viable cells and bacteria. 
(a)

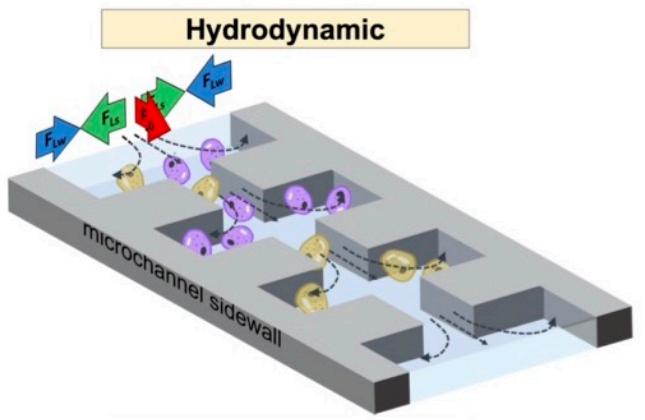

(c)

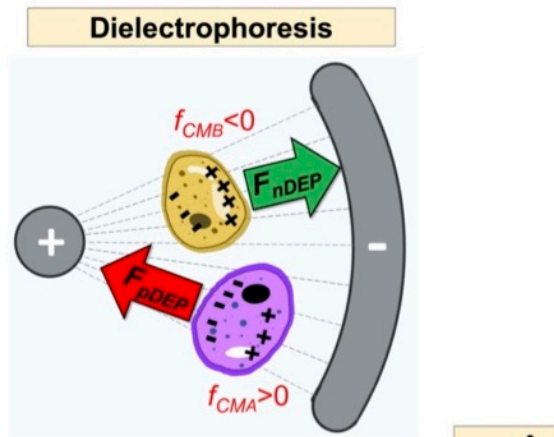

(b)

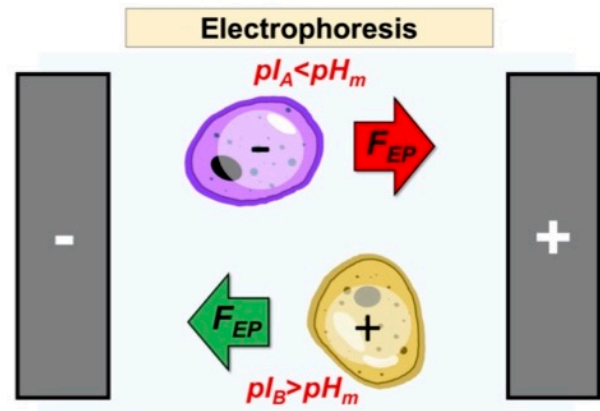

(d)

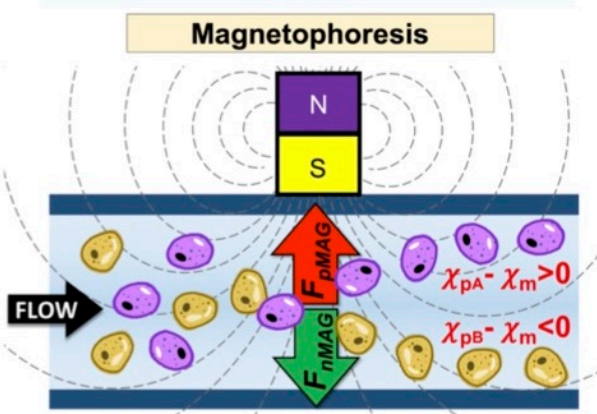

(e)

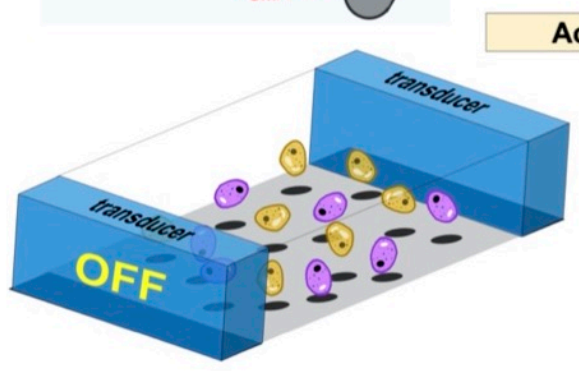

(f)

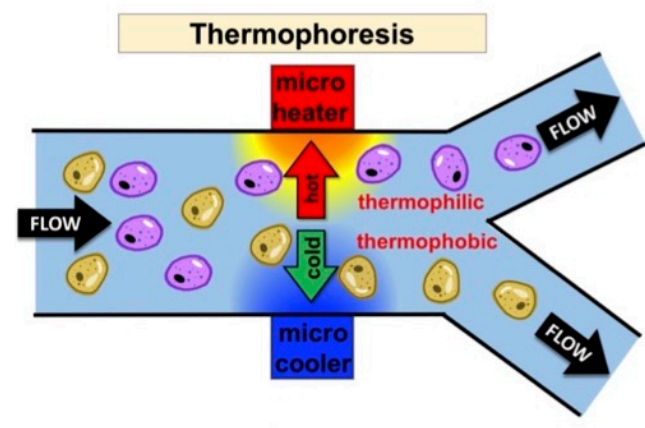

Acoustophoresis

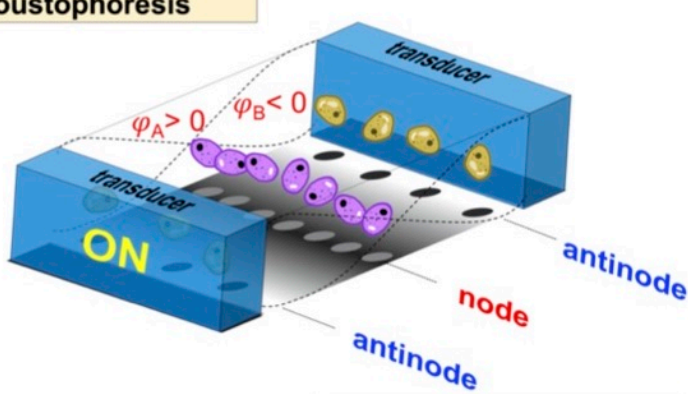

(g)

Optical Tweezing

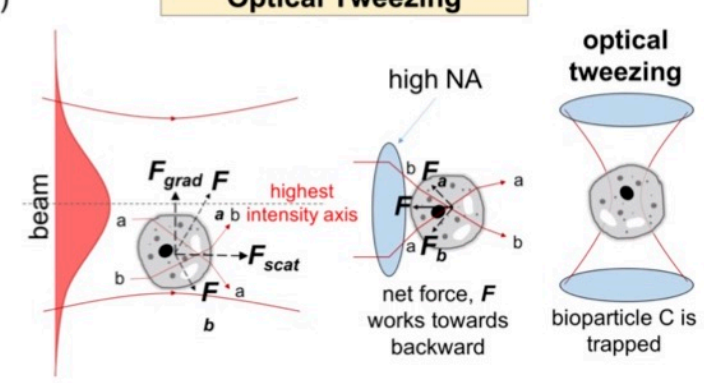

Bioparticle A

\section{LEGEND}

Bioparticle B

Bioparticle C

Fig. 1 Bioparticle active manipulation forces. (a) Hydrodynamic force. Drag force, $F_{D}$ pushes bioparticles along streamline. Inertial lift force pushes transverse to streamline, i.e. wall-induced lift force, $F_{L w}$ pushes from sidewall to stream centerline, while shear-induced lift force, $F_{L S}$ pushes in the opposite direction causing each bioparticle to converge at an equilibrium position. Sudden change of channel dimensions creates instant imbalance between $F_{L S}$ and $F_{L w}$, forming vortices to trap bioparticles. Larger size bioparticles A are trapped first than bioparticles $B$ due to higher inertial lift forces experienced. (b) Electrophoresis. Bioparticle A with a lower isoelectric point than the pH of suspending medium $\left(p l_{A}<p H_{m}\right)$, is negatively charged, thus attracted to the positive electrode. Bioparticle B with a higher isoelectric point $\left(p l_{B}>p H_{m}\right)$, is positively charged, thus attracted to the negative electrode. (c) Dielectrophoresis. At certain frequency, when polarizability is higher than suspending medium which is determined by positive $f_{C M}\left(f_{C M A}>0\right)$, bioparticle $\mathrm{A}$ is attracted to the region with maximum electric field gradients. Experiencing the opposite $\left(f_{C M B}<0\right)$, bioparticle $B$ is repelled from this region. (d) Magnetophoresis. Bioparticles $A$ experience positive magnetophoretic force, pushing them to the region with maximum magnetic flux density due to positive magnetic susceptibility difference between the bioparticles and the suspending medium $\left(\chi_{P A}-\chi_{m}>0\right)$. Experiencing the opposite $\left(\chi_{P B}-\chi_{m}<0\right)$, negative magnetophoretic force repels bioparticles B from the region. (e) Acoustophoresis. (Left) Bioparticles dispersed in the suspending medium without existence of standing acoustic wave (SAW). (Right) When SAW transducer is turned on, acoustic pressure pushes bioparticles either towards the pressure node or pressure antinode. Because of positive acoustic pressure contrast $\left(\varphi_{A}>0\right)$, bioparticles $A$ are pushed towards the pressure nodes. Bioparticles B which experience the opposite $\left(\varphi_{B}<0\right)$, are pushed towards pressure antinodes. (f) Thermophoresis. Thermophilic bioparticles A diffuse to higher temperature regions while thermophobic bioparticles B diffuse to lower temperature regions. (g) Optical tweezing. (Left) Scattering force, $F_{\text {scat }}$ pushes bioparticle $C$ away from the light source in the direction of light propagation. Gradient force, $F_{\text {grad }}$ attracts bioparticle $C$ to the peak of spatial light intensity in the direction of the optical field gradient. (Middle) Bioparticle $C$ is trapped at light focus with highest intensity when $F_{\text {grad }}>F_{\text {scat }}$, created by light emission through a high numerical aperture number lens. (Right) Bioparticle $C$ is trapped by an optical tweezer. 
Zeng et al. ${ }^{62}$ used magnetophoresis in two stages for separation of yeast mixture with PS particles. In the first stage, PS and yeast are focused along the streamline by a permanent magnet located close to microchannel. In the second stage, another permanent magnet located offset from first magnet and far from microchannel displaces the aligned particles to various flow patterns for continuous sorting. Hawkes et al. ${ }^{86}$ used acoustophoresis to transfer yeast from yeast-rich liquid stream to cell-free co-flowing stream. The laminar flow of the system maintains a stable interface between the two streams and an acoustic resonator creates a single pressure node at the centerline of the microchannel.

In addition to unicellular organisms, multicellular organisms are highly useful in genetic and pharmacological studies because of their small size, optical transparency, ease of culture, and the capability to respond to environmental stimuli. ${ }^{102,103}$ Manipulation of multicellular organisms has been demonstrated using different forces including HYD ${ }^{104-106}$ and DEP. ${ }^{85}$ Akagi et al. ${ }^{104,105}$ developed a 3D microfluidic embryo array platform driven by the HYD force for real-time developmental analysis of transgenic zebrafish Danio rerio (D. rerio) embryos. The platform is capable of performing loading, docking and addressing large numbers of embryos into an array of single-embryo traps using trap-and-release immobilization manifold (Fig. 2a). The design is optimized to induce gravitational sedimentation of embryos and low-

(a)
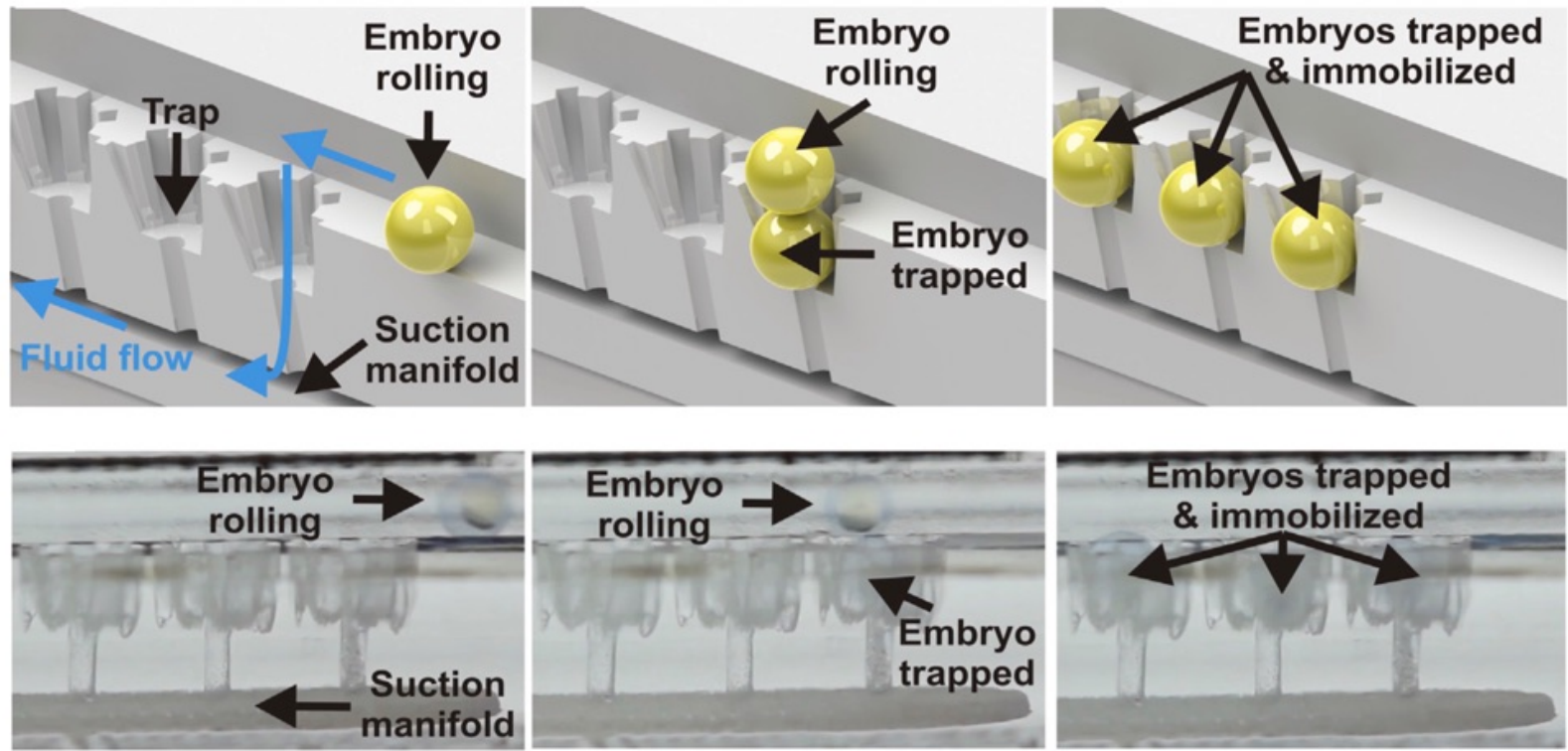

(b)
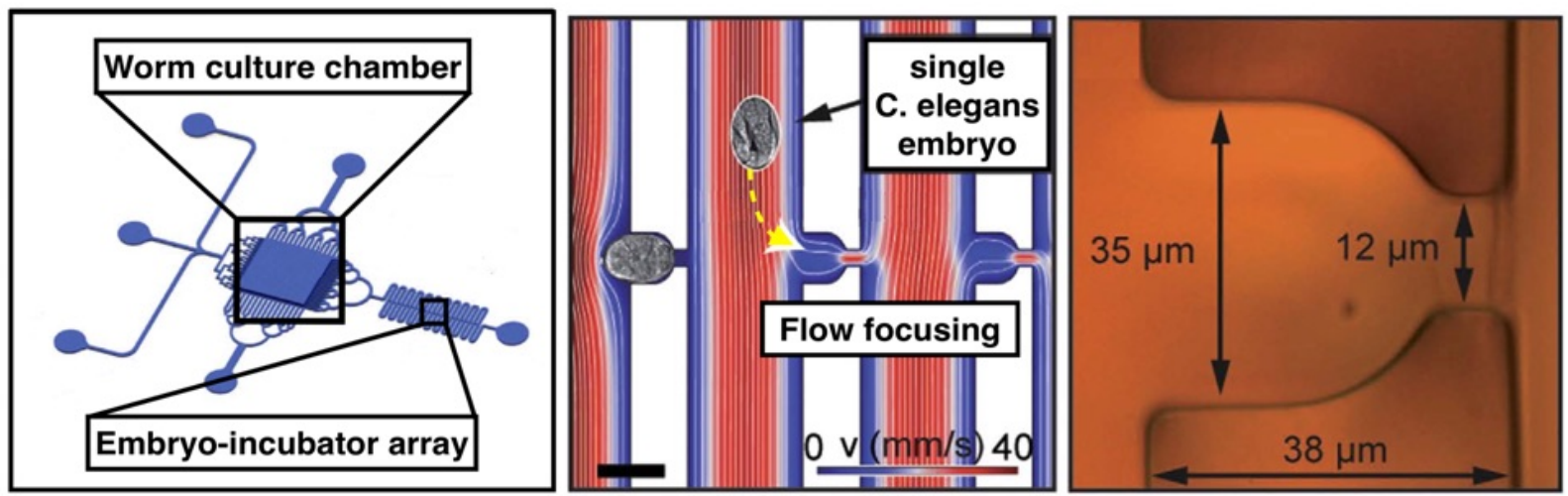

Fig. 2 Manipulation of model organisms. (a) (Above) Each zebrafish embryo is trapped and immobilized one by one in sequence at each trap by combined effect of suction flow and gravity. (Below) Cross section of microfluidic platform, showing the suction manifold induce suction flow of embryos by a micro diaphragm pump at outlet. Reprinted with permission from Akagi et al. ${ }^{105}$ Copyright 2013 Elsevier. (b) (Left) Schematic showing the structure of a microfluidic platform, consists of worm culture chamber and subsequent embryo-incubator array. (Middle) Finite element method simulation, showing the hydrodynamic arraying of single embryo at each incubator. (Right) Structure of each single embryo incubator. Reprinted with permission from Cornaglia et al. ${ }^{106}$ Copyright 2013 Nature Publishing Group. 
pressure suction for rapid trapping of single-embryos at each micro-mechanical trap. The $D$. rerio potentially provides physiological insights into human pathogenesis and therapy contributed by its neurotransmitters and a neuroendocrine system, which physiologically responds to external stimuli. ${ }^{107}$

Cornaglia et al. ${ }^{106}$ developed a HYD microfluidic platform that can provide gentle handling for real-time analysis of Caenorhabditis elegans (C. elegans) embryos (Fig. 2b). The platform immobilizes single $C$. elegans embryos in an incubator which enables investigation of organism shaping development and mitochondrial production during the full embryonic development.

Khoshmanesh et al. ${ }^{85}$ developed a DEP platform for realtime non-invasive study of nematodes with total length $200 \mu \mathrm{m}$ response under external stimuli. The nematode egg trapping and hatching were demonstrated at delta-shape region between the interfacing electrodes due to pDEP force.

Model organism manipulation involves the study of cell development and their response to different active forces. DEP, ACT and HYD forces have shown the capability of manipulating model organisms. Using DEP and ACT forces, model organisms used should be carefully selected so they exhibit similar responses to the force stimuli with the target cell. Finding model organisms which possess similar behavioral responses may be challenging. Key manipulations for model organisms are separation and immobilization of the organisms, where high processing volume is desirable. However, we notice that several research studies are still in their infancy as they demonstrate limited processing volume and microfluidic cell throughput, which is an impediment from realizing microfluidic biomedical devices. ${ }^{62,85,100,104-106}$ We include current processing volume ranges for model organism manipulation in Table 1.

\subsection{Blood cells}

Blood refers to a connective tissue composed of a liquid extracellular matrix, which suspends and dissolves various cells and cell fragments. ${ }^{108}$ Blood is composed of two components, known as blood plasma and the formed elements, including red blood cells (RBCs), white blood cells (WBCs) and platelets. Blood cell manipulation using active forces has been demonstrated in different microfluidic platforms. ${ }^{61,109-117}$ In the context of WBC separations, Bose et al. ${ }^{58}$ developed a fractionation microfluidic platform which draws neutrophils (the most abundant type of WBCs) from blood. In his work, cell adhesion proteins, which have a weak affinity with neutrophils, exert forces to attract the neutrophils which deflect it away from the blood stream into a blood-free stream under HYD forces and affinity reactions. The neutrophils are rolled over proteins due to weak adhesion and finally released at the blood-free stream (Fig. 3a).

Blood plasma contains proteins and antibodies which can be used for therapies of rare chronic conditions such as autoimmune disorders. ${ }^{118}$ In fact, plasma-free blood is also important such as in blood transfusion to patients suffering from immunoglobulin A-deficiency. ${ }^{116}$ We found a unique blood cell separation platform based on dielectrophoresis whereby RBCs, WBCs and platelets are levitated by the nDEP force. The cells are deflected to the sidewalls by the HYD force achieving plasma separation from WBCs, RBCs and platelets (Fig. 3b). ${ }^{119}$ Other demonstrations of plasma isolation and sorting based on dielectrophoresis include those by Sonnenberg et al.,120 Mohammadi et al. ${ }^{89}$ and Chen et al. ${ }^{90}$ Different DEP microelectrode configurations were employed. For example, Sonnenberg et al. used a microarray DEP electrode, Mohammadi et al. used DC with insulator based DEP microelectrodes while Chen et al. used a low-voltage $A C$ contactless DEP configuration. At high frequencies, multiple configurations can be used, however at lower frequencies, contactless microelectrodes or insulator based DEP configurations are recommended. Besides, removal of plasma protein and other low-molecular-weight compound including immunoglobulin $A$ and albumin from RBCs has been demonstrated by Tenje et al. ${ }^{116}$ using the ACT force for preparation of protein-free RBCs. In their work, RBCs are prealigned by acoustic standing wave into the same flow region of the parabolic flow at a pre-alignment zone and later transferred laterally into a buffer solution stream at the channel centerline along the separation zone to the center outlet, while plasma and plasma proteins are moved to the channel sidewall as waste at side outlets.

In terms of achieving blood fractionation, ${ }^{101,121}$ Jung et al. ${ }^{63}$ developed a microfluidic platform that can enrich RBCs and WBCs from peripheral blood utilizing native magnetic and dielectric properties of blood cells. DEP and MAG forces were applied in opposite lateral directions resulting in the separation of WBCs. We are of the opinion that the works conducted by Yan et al. ${ }^{119}$ could be enhanced by combining the platform separation methodologies employed by Jung et al. so the resulting microfluidic platform can conduct whole blood fractionation i.e. it is able to comprehensively separate RBCs, WBCs platelets and plasma. The biomechanical response of cells and its deformation characteristics give insight into its pathological state. Du et al. ${ }^{122}$ developed a microfluidic platform for detection of malaria infection by utilizing pDEP forces to induce cell stretching due to polarisation. The stretching ratio of the cells is then measured to distinguish between the infected RBC (iRBC) and healthy RBC (hRBC) in vitro (Fig. 3c). Utilizing similar deformability characteristics, Fook Kong et al. ${ }^{87}$ separated malaria iRBCs using the stiffness difference of iRBCs and hRBCs using HYD forces. The iRBCs which are stiffer, were segregated towards the microchannel wall, while wall induced pressure gradients pushed the hRBCs towards the center effectively separating iRBCs from hRBCs of different infection stages.

Martel et al. ${ }^{61}$ demonstrated volume reduction based on a continuous concentration of suspended WBCs using HYD forces (Fig. 3d). Blood was accelerated by channel convergence and focused by HYD inertial forces, while the cell-free suspension medium was pushed to the outer walls. The process was repeated until the desired volume reduction ${ }^{101}$ was achieved. This platform managed to concentrate WBCs with a volume reduction of more than 400 times with a yield above 95 percent at $4 \mathrm{~mL} / \mathrm{min}$ throughput. 
As blood consists of different cells and cell fragments, manipulation of RBCs or certain WBCs in native blood conditions can be challenging. ${ }^{123}$ Plasma isolation or manipulation of blood cells in their non-native environments and concentrations have been researched using DEP119 and HYD $^{61}$ forces, primarily in the separation and fractionation processes. DEP processes has shown capability in manipulating healthy RBCs from infected RBCs, showing potential for the realization of a DEP based diagnostic platform. ${ }^{87,122}$ Blood separation and fractionation with large processing volume is highly desired. The problems currently faced lie in its relatively low throughput which prevents its conversion to a microfluidic clinical device. ${ }^{63,87,120}$ MAG forces have the advantage of higher selectivity but requires research of side effects of applying these forces on cellular and physiological health. ${ }^{124}$ We included processing volume rate for blood separation and fractionation in Table 1.

\subsection{Tumor and cancer cells}

Tumor cells are cells that proliferate excessively in an uncontrolled fashion which cause the development of an abnormal massive tissue generally known as a tumor. Tumors (a)

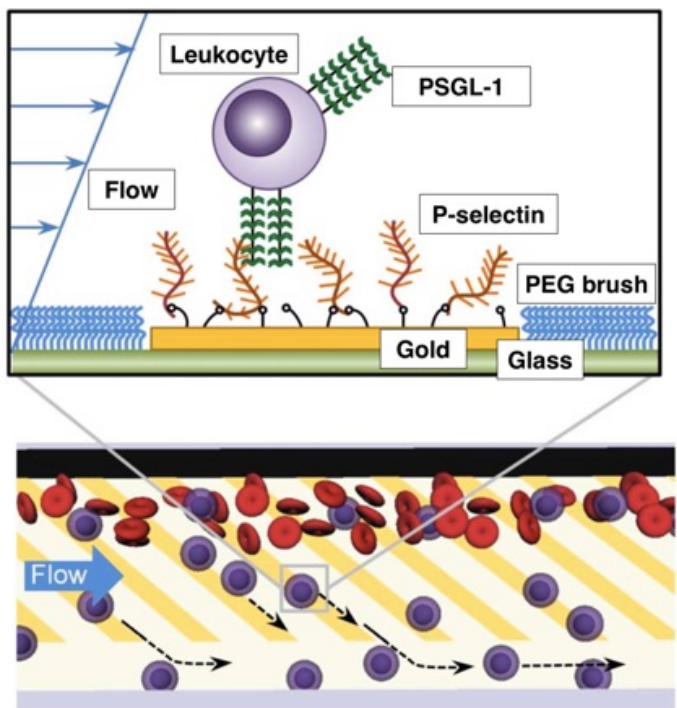

(b)

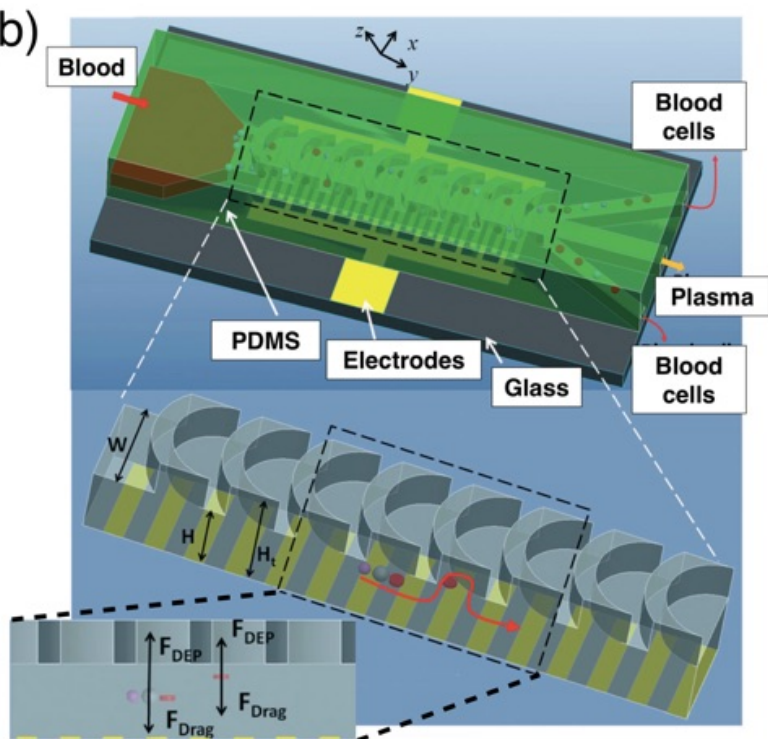

(c)
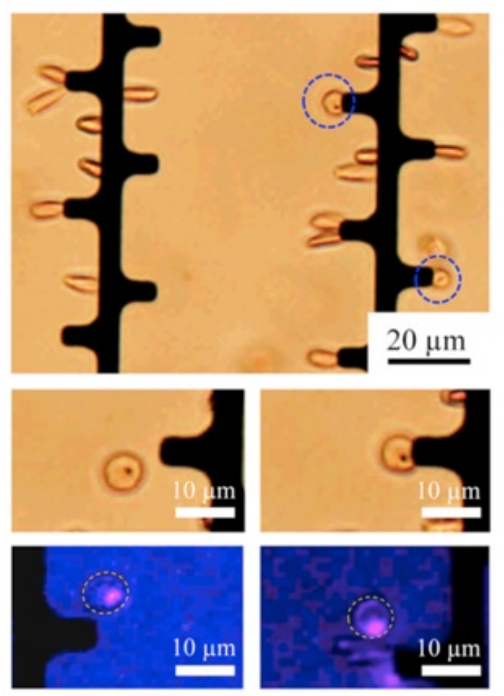

(d)

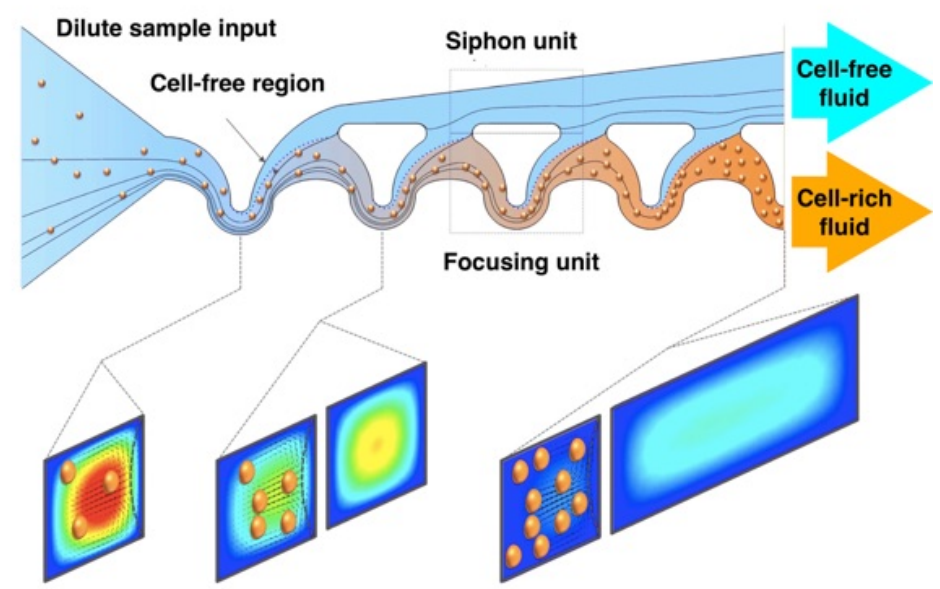

Fig. 3 Manipulation of blood cells. (a) (Above) Neutrophils are isolated from blood using weak affinity reactions between neutrophils with cell adhesion proteins, P-selectins. (Below) Neutrophils interact with asymmetrically patterned P-selectins, roll on them, and get transferred from blood stream to the co-flowing buffer stream. Reprinted with permission from Bose et al. ${ }^{58}$ Copyright 2013 Nature Publishing Group. (b) Plasma blood is isolated from blood. Blood cells experience nDEP pushing them upward by electrodes at the lower side, and later above the layer, they are pushed to the sidewall by stearic hindrance, leaving plasma blood at the middle outlet. Reprinted with permission from Yan et al. ${ }^{119}$ Copyright 2014 Royal Society of Chemistry. (c) Healthy RBCs experience stretching by pDEP exerted by the electrode. Malaria infected RBCs are not stretched due to the decrease of deformability. Reprinted with permission from Du et al. ${ }^{122}$ Copyright 2014 Elsevier. (d) Volume reduction or concentration of blood samples. Blood cells are attracted to the curved inner wall due to repetitive inertial focusing, leaving the outer wall free of blood cells. Reprinted with permission from Martel et al. ${ }^{61}$ Copyright 2015 Nature Publishing Group 
become cancerous when they are malignant, otherwise, they are benign. ${ }^{125,126}$ Tumors and cancers develop at the lungs, breasts, prostate, rectum, colon and skin. They are categorized as either carcinomas which develop in epithelial cells, or leukaemia and lymphomas which develop at the blood and lymphatic system, or sarcomas which develop at connective tissue cells. ${ }^{127}$ The primary tumor cells can spread via the vascular or blood vessel network, which is known as circulating tumor cells (CTCS). Secondary developed tumor caused by CTCs is called the metastasis tumor, which is responsible for the majority of cancer-related fatalities. ${ }^{128}$

Development of microfluidic systems dealing with manipulation of tumor cells has been focused on the detection and separation of the cells from sample. Different forces have been applied including the HYD, ${ }^{26,97,99}$ DEP, ${ }^{51,98}$ MAG $^{97,99}$ and ACT 70,129 forces.

Karabacak et al. ${ }^{99}$ demonstrated isolation of CTCS of prostate, lung and breast cancer cells from blood samples using lateral displacement, inertial focusing and magnetophoresis (Fig. 4a). Lateral displacement removes nucleated cells from whole blood. Inertial focusing concentrates labelled and unlabelled cells at the channel centerline to increase sensitivity of separation at magnetophoresis stage. Sollier et al. ${ }^{26}$ demonstrated isolation of CTCs from blood sample using HYD forces involving microscale vortices and inertial focusing. A microfluidic channel is provided with channel expansion regions functioning as a trap. When entering the microfluidic path at (a)

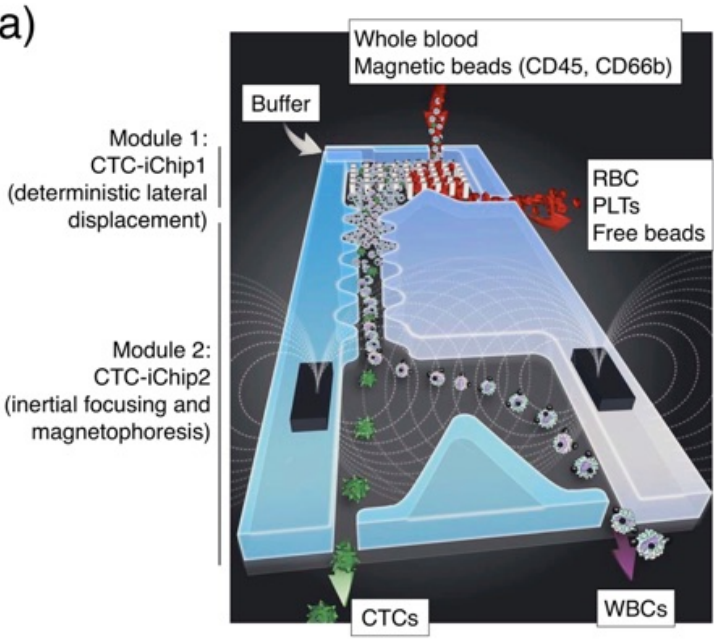

(b)

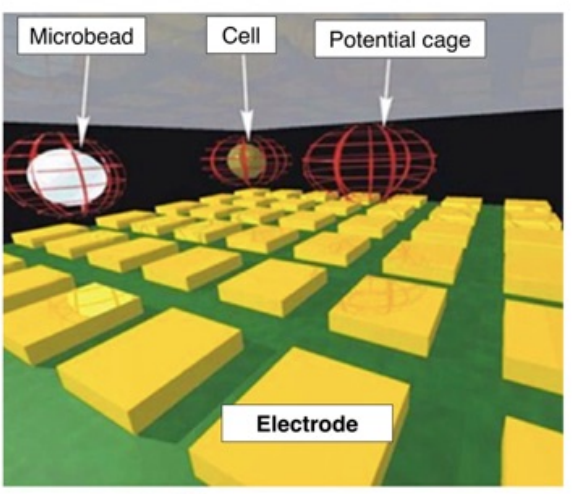

Cells entrapment in DEP cages

(c)

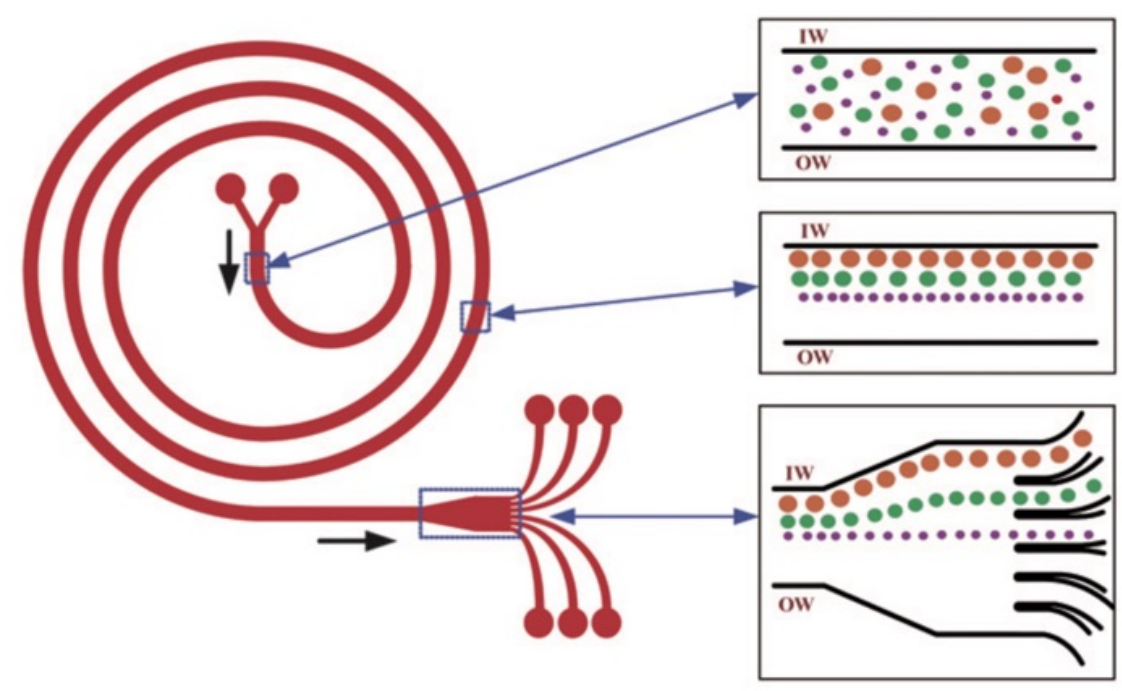

Fig. 4 Manipulation of tumor and cancer cells. (a) Isolation of CTCs from whole blood. Nucleated cells are separated by deflection of the pillar array at first stage. Remaining cells which are CTCS and WBCs are focused to a streamline by inertial focusing and later separated by magnetophoresis. Reprinted with permission from Karabacak et al. ${ }^{99}$ Copyright 2015 Nature Publishing Group. (b) Isolation of CTCs. Single cells are trapped in DEP cage. Each cell that detected as CTC, will be moved via software controlled modulated electrical fields to downstream analysis. Reprinted with permission from Fabbri et al. ${ }^{51}$ Copyright 2013 Elsevier. (c) Separation of neuroblastoma and glioma cells by a spiral microchannel. Each particle equilibrate at different equilibrium position along the inner wall of the microchannel under the influence of inertial lift force and Dean force, sorting the bioparticles. Reprinted with permission from Kuntaegowdanahalli et al.60 Copyright 2009 Royal Society of Chemistry. 
expanded regions, CTCs are largely repelled from the channel centerline relative to other blood cells because they are larger in size, forcing them to be trapped, while the blood cells flow through.

Fabbri et al. ${ }^{51}$ used dielectrophoresis to generate DEP cage for trapping, detection and sorting of lung CTCS and lymphocytes from whole blood (Fig. 4b). The CTCs are routed from a DEP cage by modulation of electrical fields for downstream molecular analysis. Salmanzadeh et al. ${ }^{98}$ demonstrated separation of prostate tumor initiating cells and non-tumor initiating cells using contactless dielectrophoresis. They performed the separation based on the difference of membrane surface proteins and their electrical charge.

Hyun et al. ${ }^{97}$ demonstrated isolation of human breast cancer from blood using a two-stage microfluidic isolation method. At the first stage, WBCs which coat antibody conjugated magnetic nanoparticles are captured by magnetophoresis while other cells pass through. At the second stage, cells are focused at the center of the channel by inertial HYD force followed by coating with epithelial cell adhesion molecule (EpCAM) antibody, where the EpCAM positive cells are captured and EpCAM negative cells pass through.

Antfolk et al. ${ }^{70}$ demonstrated separation of prostate cancer cells from WBCs using acoustophoresis. The ACT force is used to perform pre-alignment of cells and later separation of target cells based on their size, density and compressibility. Besides, Li et al. ${ }^{129}$ demonstrated acoustophoresis based isolation of human breast cancer cells in viable states from peripheral blood samples. Acoustophoresis is known to preserve integrity, functionality and viability of biological cells contributed by label-free and contact-free configuration. ${ }^{130}$

Microfluidic systems have been developed for studying cancer cell line authentication as there are cases reported of misidentified human cell line usage. ${ }^{131,132}$ An et al. ${ }^{133}$ studied cell line authentication by capillary electrophoresis which is used in genotyping. ${ }^{134}$ The study was based on short tandem repeat (STR)-PCR involving co-amplification of a panel of STR loci by multiplex PCR and downstream fragment length analysis.

Studies of cancer cells in microfluidic systems involves the quantitative study of properties or response of cancer cells toward particular forces and the development of diagnostic tools base on separation. Because cancer cells are classified as rare cells, general properties of the cells compared to healthy cells can seem indefinite and need to be studied. Studies of cancer cell manipulation properties has been done using the $\mathrm{DEP}, 47,92 \mathrm{ACT}^{135}$ and OPT 96 forces.

Mulhall et al. ${ }^{47}$ developed a DEP microwell platform for cell electrical properties measurement. They measured cell electrical properties of healthy cell and oral cancer cell based on cell motion in the microwell by assessment of light intensity changes. Results showed that disease progression contributes to decreasing cytoplasmic conductivity and effective membrane capacitance. Diagnostic tools can be developed based on the understanding obtained by this study for detection of oral squamous cell carcinomas which is the most common skin cancer. ${ }^{136}$
Leroy et al. ${ }^{92}$ used microwave frequency based DEP microtips to trap colorectal cells and conduct dielectric spectroscopy of non-cancerous and cancerous cells. Intracellular properties including membrane capacitance have been investigated. Guo et al. ${ }^{135}$ used acoustic wells generated by two orthogonal SSAW to control distance and interaction of leukaemia cells. They performed the study of dye transfer between the cells. Zhang et al. ${ }^{96}$ used near-infrared laser beam to investigate the transit time difference between healthy skin cells and melanoma cells. The laser beam creates an OPT gradient force adjacent to the focusing point which influences the transit time. Results show consistent significant differences between healthy skin cells and melanoma cells transit time. This understanding can contribute to the development of melanoma cancer diagnostic tools.

Microfluidic systems for cancer cells detection and separation have been demonstrated using different forces include HYD,60 EP, 91 DEP, ${ }^{93}$ MAG $^{57}$ and ACT. 94,95 Kuntaegowdanahalli et al. ${ }^{60}$ conducted separation of neuroblastoma and glioma cells based on combination of inertial and rotational forces in a spiral microfluidic platform. The ratio of inertial and rotational forces determines at which position particles equilibrate. The cells were focused at distinct equilibrium positions depending on their size, and collected at different outlets (Fig. 4c).

Deng et al. ${ }^{91}$ isolated bladder cancer cells from urine based on electrophoresis. The urine is first filtered by a membrane to obtain mutated genes and methylated genes and then amplified by PCR. The genes are then identified and isolated by the EP force. Sano et al. ${ }^{93}$ performed continuous sorting of human leukaemia cells from diluted blood samples using contactless dielectrophoresis, where electrodes are isolated from the microfluidic channel by a thin membrane. Using this system, the leukaemia cells were successfully manipulated without affecting RBCs in the suspending medium. Schneider et al. ${ }^{57}$ also demonstrated sorting of leukaemia cells, however, using magnetophoresis. In this method, cells are first immuno-magnetically labelled with antibodies conjugated with magnetic nanospheres. With the isodynamic magnetic field, an orthogonally oriented thin stream of cell suspension in continuous sheath flow is formed which induces the sorting. Shields et al. ${ }^{94}$ demonstrated separation of leukemica cells by trapping them with biofunctionalized elastomeric silicon particles and transport the cells to pressure antinodes under SSAW pressure. Ding et al. ${ }^{95}$ performed separation of breast cancer cells from a mixture of WBCs by using SSAW pressure having a tilted directional angle relative to flow direction.

Detection and isolation of CTCs in peripheral blood is generally regarded as the objective of tumor and cancer cell manipulation. However, the heterogenic nature of the CTC poses a great challenge to achieve this objective. Thus, though proof-of-concept studies have been demonstrated, CTCs detection microfluidic platforms have not been commercialized due to vast heterogeneity of fluids which suspend the CTCs. ${ }^{137,138}$ The DEP force has shown potential in the development of cancer diagnostics and therapeutics as it is able to manipulate bioparticles according to the difference in 
electrical properties of non-cancerous cells and cancerous cells. However, DEP manipulation has exhibited lower selectivity in cases where the dielectric properties of cancer cells and other bioparticle candidates in its native suspending medium are too close or similar to each other. An exception to this occurs if the process is computer-assisted or realized using DEP automations on a chip. ${ }^{51,98,139}$ MAG force has the advantage of high selectivity even though it generally requires a labelling process. ${ }^{19}$ ACT force also has shown capability of isolating cancer cells from WBCs, with the assistance of affinity-based capturing. However, the lack of applications demonstrated in isolating cancer cells from peripheral blood, CTCs' wide heterogeneity and lack of selectivity require for further research. ${ }^{70,129}$ The OPT force can be used for the study of differentiating healthy cells and cancerous cells, however its limited scope at the present time indicates that further study is required for manipulating unknown cancer cells. ${ }^{92}$ Recent processing volume ranges achieved for tumor and cancer cells manipulation is within $2 \mu \mathrm{L} / \mathrm{min}$ to $7 \mathrm{~mL} / \mathrm{min}$ (Table 1). The nature of active manipulation requires that properties of these fluids should be understood to allow accurate detection and manipulation. There are opportunities for future research particularly in determining the physical properties of cancerous cells and non-cancerous cells related to the active manipulation fundamentals.

\subsection{Stem / progenitor cells}

Stem cells are cells with the ability to self-renew, generating perfect copies of themselves upon division and differentiate, which produce specialized cell types that perform specific functions in the body. ${ }^{3}$ Stem cells are categorized into adult stem cells and pluripotent stem cells. ${ }^{140}$ Pluripotent stem cells can be used for producing large numbers of useful cells to conduct research, perform drug screening or enable cell transplantation therapy. ${ }^{3}$ Development of a microfluidic system for stem cells has several purposes, including separation or extraction of progenitor cells, introduction of manipulating particles into progenitor cells and seeding of progenitor cells into porous scaffold for tissue engineering. Separation and extraction of progenitor cells have been demonstrated using DEP141,142 and MAG 110,143 forces.

Muratore et al. ${ }^{142}$ used dielectrophoresis in performing isolation of multipotent myoblastic cells from mixed population of cells without the use of a biological tag. Specific cell types could be recovered based on the cross-over frequencies, $f_{x o}$ of the cells, in addition to the quadrupole funnel type electrode arrangement. $\mathrm{Ng}$ et al. ${ }^{141}$ demonstrated a rapid label-free detection of endothelial progenitor cells from small volumes of WBCs samples. They used a microelectrode array silicon chip which exerts nDEP force for cell trapping, surface immunochemistry for selective cell capture and fluidics for cell washing and impedance detection (Fig. 5). This study is relevant for the development of point-ofcare (POC) cardiovascular diagnostic tools indicated by circulating endothelial progenitor cell levels in blood. ${ }^{144}$

Jing et al. ${ }^{110}$ used magnetophoresis for isolation of hematopoietic progenitor cells ${ }^{145}$ from WBCs sample taken from blood. After labelling with antibody and magnetic colloid
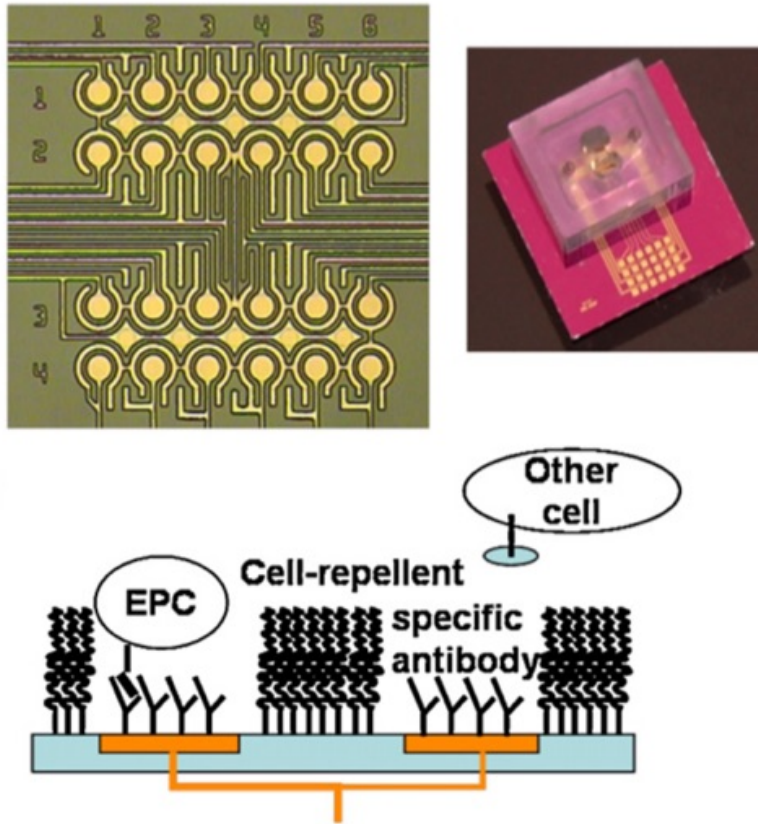

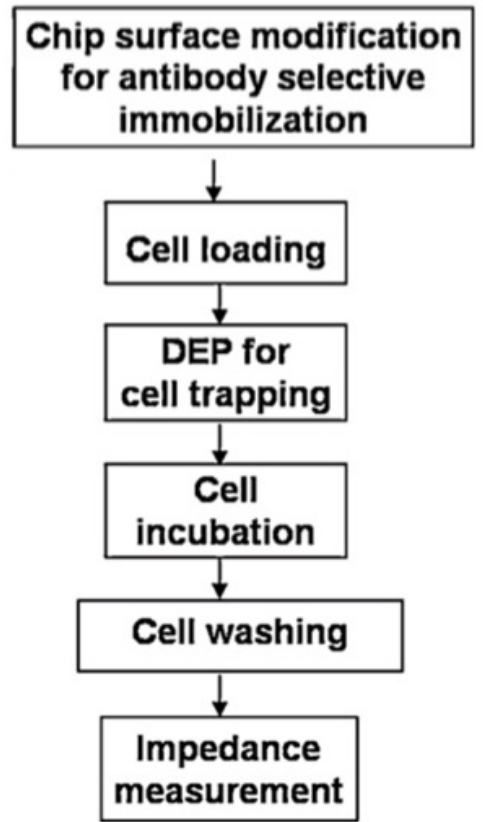

Fig. 5 Manipulation of stem cells. (Left above) Endothelial progenitor cells (EPCS) are trapped by nDEP using horse-shoe shaped surrounding electrode with round shaped electrode at center. Minimum electric field is generated at the center of a round electrode and at the gap in-between electrodes, while maximum electric field is generated at the edges of both electrodes. (Left below) EPCS are trapped at the center of the round electrode when they are repelled from the edges to the center of round electrodes by nDEP and selectively captured by antibodies. (Right) EPCs are incubated in the platform while unattached cells are washed away for impedance detection. Reprinted with permission from Ng et al. ${ }^{141}$ Copyright 2010 Elsevier. 
against non-progenitor leukocytes, hematopoietic progenitor cells were separated by a quadrupole magnetic flow sorter, resulting into a split-flow thin-cell fractionation. ${ }^{146}$ Wilson et al. ${ }^{143}$ separated human umbilical vein endothelial cells from PBS using magnetic chains. The magnetic chains are magnetic nanoparticles with composite configuration that can form chains under magnetic field. In this method the cells are first immunomagnetically labelled and then bound to the magnetic chains.

Manipulation of progenitor cells has been performed with the MAG force. ${ }^{147,148}$ Wilhelm et al. ${ }^{147}$ developed a cellular magnetic labeling technique using endocytosis. Endocytosis is the process of transporting magnetic nanoparticles into endothelial progenitor cells by engulfing the nanoparticles in an energy-using process. The cells' plasma membrane adsorbs the anionic magnetic nanoparticles by their negative surface charges. Endothelial progenitor cells have therapeutic potential for revascularization of an organ that suffers from ischemia or restriction in blood supply to tissues.

Rivière et al. ${ }^{148}$ performed a biocompatibility study of labelling procedures of myogenic precursor cells by anionic iron oxide nanoparticles and on applicability study for noninvasive magnetic resonance imaging (MRI). Myogenic precursor cells have the potential of providing muscle disorder therapy by autografting or tissue transplantation. ${ }^{149,150}$

Seeding of progenitor cells into porous scaffolds for tissue engineering has been performed with the MAG force. ${ }^{151}$ Robert et al. ${ }^{151}$ used magnetic tweezers to manipulate, probe and position progenitor cells labelled with iron oxide magnetic nanoparticles into a porous scaffold. ${ }^{152}$ They investigated seeding of local viscosity of the scaffolds internal channels and stiffness of the scaffolds pore using the MAG force acting on magnetic nanoparticles.

Stem cells manipulation has been extensively studied using MAG and DEP forces. The MAG force has the advantage of high selectivity if used in combination with affinity-based interaction, which is benefited by an advancement of magnetic nanoparticle behavior research. However, these processes require biofunctionalization of the magnetic nanoparticles.

As magnetic nanoparticles are used for manipulation, studies to understand the effect on cellular physiological behaviors should be conducted before clinical applications can be realized. DEP manipulation, on the other hand, does not require biofunctionalization, but requires further investigation of stem cell behaviors and responses towards the DEP force. ${ }^{50}$

\subsection{Bacteria}

Bacteria consist of a huge domain of unicellular prokaryotic microorganisms. ${ }^{153}$ Bacteria size ranges between $0.5-5.0 \mu \mathrm{m}$ in length, which is around one-tenth the size of eukaryotic cells. Their shape varies, include spheres, rods and spirals.1,153,154 They grow and reproduce rapidly through binary fission. ${ }^{154}$ They act either as predators, mutualists or pathogens with other organisms. Pathogenic bacteria form a parasitic association with other organisms and cause infections such as tetanus, typhoid fever, diphtheria, syphilis, cholera, foodborne illness, leprosy and tuberculosis. ${ }^{155}$
Among important roles of bacteria in biomedicine are diagnosis of diseases and the study of biological responses of bacteria under certain stimuli. ${ }^{153,154}$ In these studies, bacteria need to be separated or isolated from blood or the suspending environment and be immobilized in diagnosis or research platforms. Thus, implementation of microfluidic devices for biomedical applications requires features such as separation, isolation and immobilization of the bacteria. The MAG force has been shown as advantageous amongst all manipulation methods when assisted with affinity reaction.

Different methods include EP,37 DEP ${ }^{156-158}$ and MAG 159 forces have been applied for separation or isolation of bacteria from a mixed sample. Oukacine et al. ${ }^{37}$ demonstrated focusing of Micrococcus luteus ( $M$. luteus) bacteria using electrophoresis. M. luteus is a gram-positive bacteria that colonize the human mouth, mucosae, oropharynx and upper respiratory tract. ${ }^{160,161}$ Bisceglia et al. ${ }^{156}$ separated $E$. coli bacteria from blood using dielectrophoresis with an interdigitated electrode configuration. $E$. coli are trapped at the electrode by the PDEP force while blood cells are repelled by the nDEP force at a designated AC frequency. Cha et al. ${ }^{157}$ also used dielectrophoresis to perform trapping of $E$. coli by the pDEP force. The suspending medium in their work is in droplet mode, however, the trapping mechanism is at the microscale level. He et al. ${ }^{158}$ conducted trapping of Salmonella typhimurium (S. typhimurium) bacteria using dielectrophoresis assisted with fluorescent nanoparticles labelling (Fig. 6a). In this method, S. typhimurium which is incubated with the antiS. typhimurium antibody was conjugated with fluorescent nanoparticles to form bio-conjugates. In this microfluidic platform, bio-conjugates experience pDEP force and are attracted towards the electrodes while non-conjugates flow away from the electrodes because of the nDEP force. S. typhimurium is one of common foodborne infectious pathogens. Lee et al. ${ }^{159}$ demonstrated separation of E. coli from bovine whole blood using magnetophoresis. They used magnetic nanoparticles modified with a synthetic ligand to trap E. coli and immobilize them adjacent to the channel wall due to magnetic field exerted by three permanent magnets located in series along the microchannel side wall.

Bacteria manipulation in biomedical research has also been demonstrated using several methods, such as MAG ${ }^{64}$ and OPT forces. ${ }^{78}$ Kinnunen et al. ${ }^{64}$ used the MAG force to develop a biomedical platform capable of continuous bacteria growth monitoring by utilizing asynchronous magnetic bead rotation sensors (Fig. 6b). In this work, E. coli is attached to the magnetic bead, which is then manipulated in rotational motion within a magnetic field exerted by an electromagnetic coil. E. coli growth can be monitored by observation of the rotational period change, which is caused by the increase in the bead bacterium.

Liu et al. ${ }^{78}$ developed a biomedical platform for monitoring cell-cell interactions using an optical tweezer (Fig. 6c).They produced OPT forces at a tapered fiber probe tip using a 980 $\mathrm{nm}$ wavelength laser beam and formed E. coli cell chains as well as trap, remove and reorder the sequence of the $E$. coli chain for study of cell contact sequence. 
One of the motivations of manipulating bacteria lies in the detection of pathogen-act bacteria. Detection, isolation and and immobilization of bacteria requires for low to high processing volumes. Current studies have shown manipulation ranges from $170 \mathrm{~nL} / \mathrm{min}$ to $1 \mathrm{~mL} / \mathrm{min}$ (Table 1). This has been extensively studied in affinity-based methods, including the MAG ${ }^{159}$ and DEP 158 forces. The affinity-based MAG method requires sample preparation procedures, such as functionalization and incubation which increases process complexity especially for on-site disease diagnostics. However, some studies show the potential of non-affinity based methods to work well using DEP-based manipulation but they exhibit limitation in selectivity of candidates. ${ }^{157}$ OPT manipulation has also shown capability in manipulating bioparticles particularly in cell chain assemblies. ${ }^{78}$ However, these demonstrations are more suitable for cell-cell interaction studies and do not signify an immediate translation into a commercial diagnostic or therapeutic device due to poor selectivity in its native environment.

\subsection{Viruses}

Viruses are essentially genes enclosed by a protective coat. ${ }^{1}$ Their size is around 15 to $200 \mathrm{~nm}$ in diameter, and they contain double or single stranded DNA or RNA. They are infective agents as they do not possess any element of metabolic machinery and depend on the host for assistance in gene expression. ${ }^{162,163}$ However, recent research has found potential utilization of viruses as biological vehicles for delivery into cells and encapsulation of inorganic and organic molecules. ${ }^{164}$

Virus detection for disease diagnosis is the most important role of virus manipulation in biomedicine in addition to other roles such as the study of virus influence to cells. To detect the existence or infection of virus in a system, virus which is suspected of infecting a system needs to be trapped, concentrated and later detected with a suitable biomarker. Forces including HYD, 165-167 DEP, 168,169 MAG170 and OPT169,171 have been employed in manipulation of virus in detection and also for biomedical studies.

Hosseini et al. ${ }^{165}$ developed microfluidic discs coupled with microspheres for detection of dengue virus. Microfluidic discs perform micro mixing based on the HYD force to enable enhanced molecular interaction between microspheres and the dengue virus. Biofunctionalized polymethacrylate microspheres trap the dengue virus for detection as they are micro mixed. Aeinehvand et al. ${ }^{166}$ improved the micro mixing with a micro balloon mixing method which produces consistent periodical 3D reciprocating flow by expansion and contraction of the micro balloon. The system was capable of detecting dengue infection in 5 mins, which shows significant improvement compared to conventional methods that require approximately 2 hours. Early detection of dengue virus is (a)

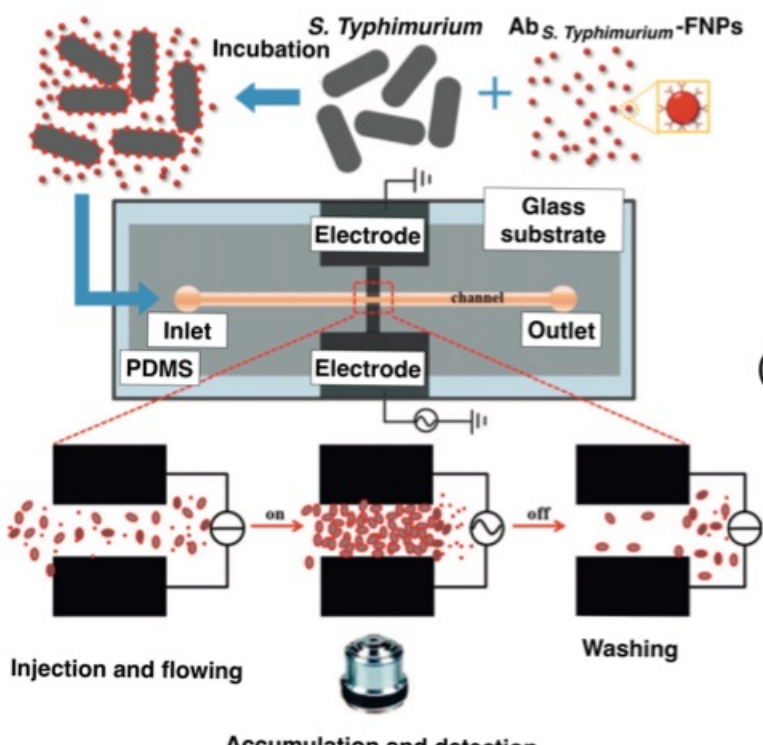

(b)
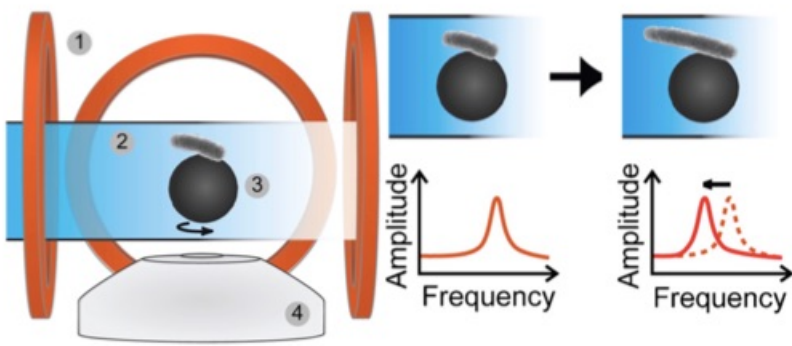

(c)
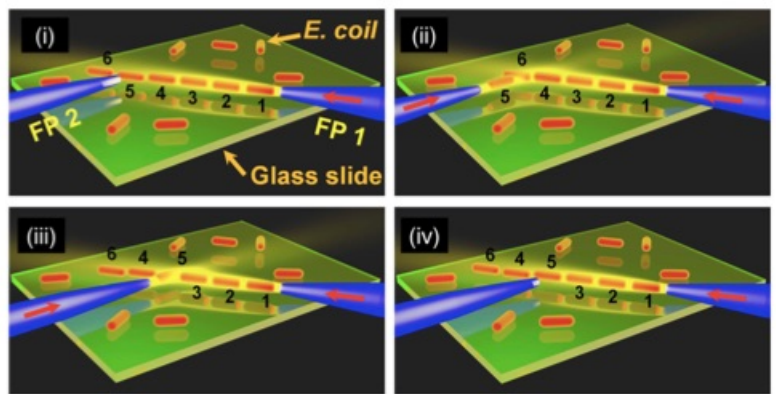

Fig. 6 Bacteria manipulation. (a) Trapping and accumulation of bacteria cells for detection. S. typhimurium are first incubated with fluorescent nanoparticles. They are then introduced into a microfluidic channel and trapped at the detection region by pDEP when electric field is applied. Reprinted with permission from He et al. ${ }^{158}$ Copyright 2013 Elsevier. (b) Observation of bacteria growth using asynchronous magnetic bead rotation (AMBR) sensing. E. coli is attached to a magnetic bead, which is then manipulated in a rotating magnetic field. The bacteria growth or elongation is observed for a change of the rotation period. Reprinted with permission from Kinnunen et al. ${ }^{64}$ Copyright 2011 Elsevier. (c) Formation of the E. coli chain by OPT force. Laser beam injection to fiber probe is used to trap bacteria at the probe tip. By turning on and off the laser injection, bacteria is rotated and oriented toward the axial direction of the laser beam, thus it can be trapped, formed a chain and change the sequence. Reprinted with permission from Liu et al. ${ }^{78}$ Copyright 2015 Nature Publishing Group. 
highly crucial to prevent progress from dengue fever to dengue hemorrhagic fever where plasma leakage will lead to mortality. ${ }^{172-174}$ In another study, Chang et al. ${ }^{170}$ used magnetophoresis to develop dengue infection diagnosis platform. A dengue virus containing sample is first mixed with both biofunctionalized superparamagnetic particles and fluorescent particles. Interaction between the viruses and the particles form fluorescent-virus-magnetic complexes. The complexes were then separated from the sample by the MAG force and detected by transmission of bright field and epifluorescence microscopy.

Mu et al. ${ }^{167}$ utilized the HYD force to develop a microfluidic paper-based diagnosis platform for hepatitis $\mathrm{C}$ virus by detection of human immunoglobulin antibody. The platform consists of two steps based on a serological immunoassay that uses antibodies and color changes to identify the existence of the virus. The first step involves an enzyme-linked immunosorbent assay, ${ }^{163}$ while the second step involves a recombinant immunoblot assay. ${ }^{175}$ As a note, hepatitis $C$ is a viral infection worldwide with around 170 million people infected to date. ${ }^{176}$ Despite its criticality, there is a serious lack of development of rapid microfluidic based diagnostic technology for this disease.

Nakano, Ding and Suehiro ${ }^{168}$ developed DEP microfluidic platform for detection of adenovirus and rotavirus (Fig. 7a). The viruses are attracted by the pDEP force, which immobilizes them to the electrodes. Change of impedance and conductance across the electrodes indicate the existence of (a)

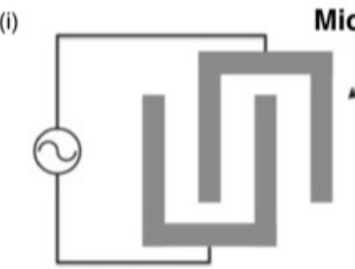

(ii)

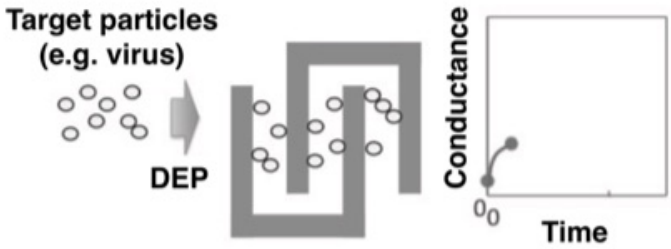

(iii)
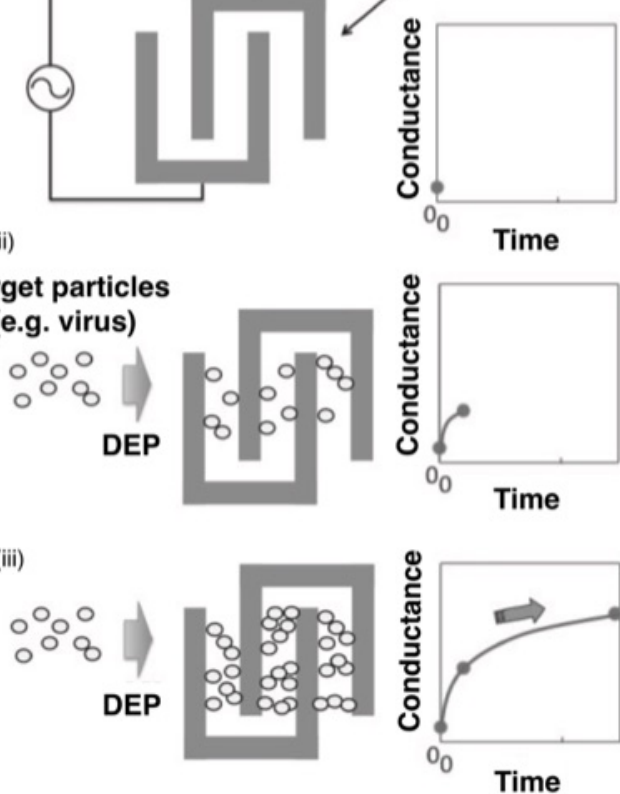

(b)

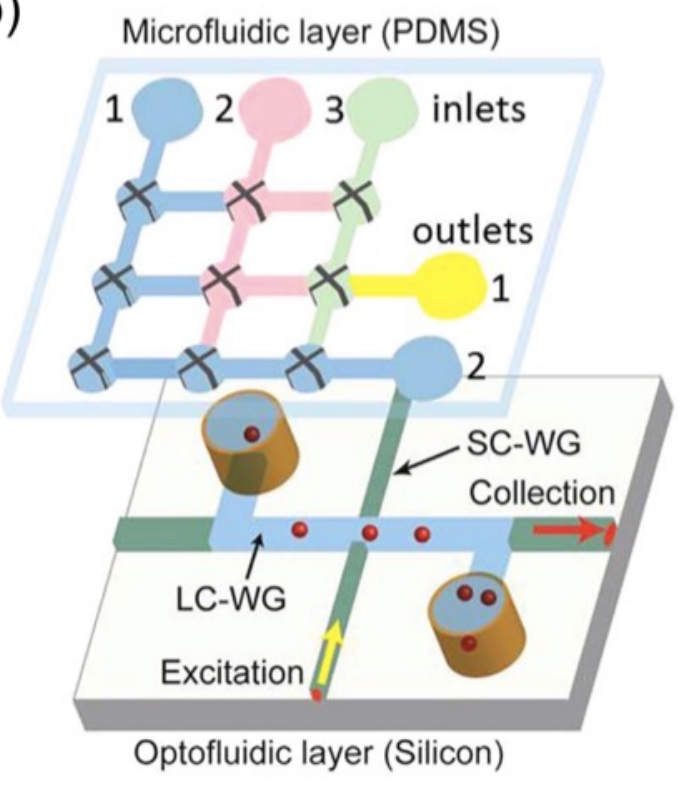

(c)
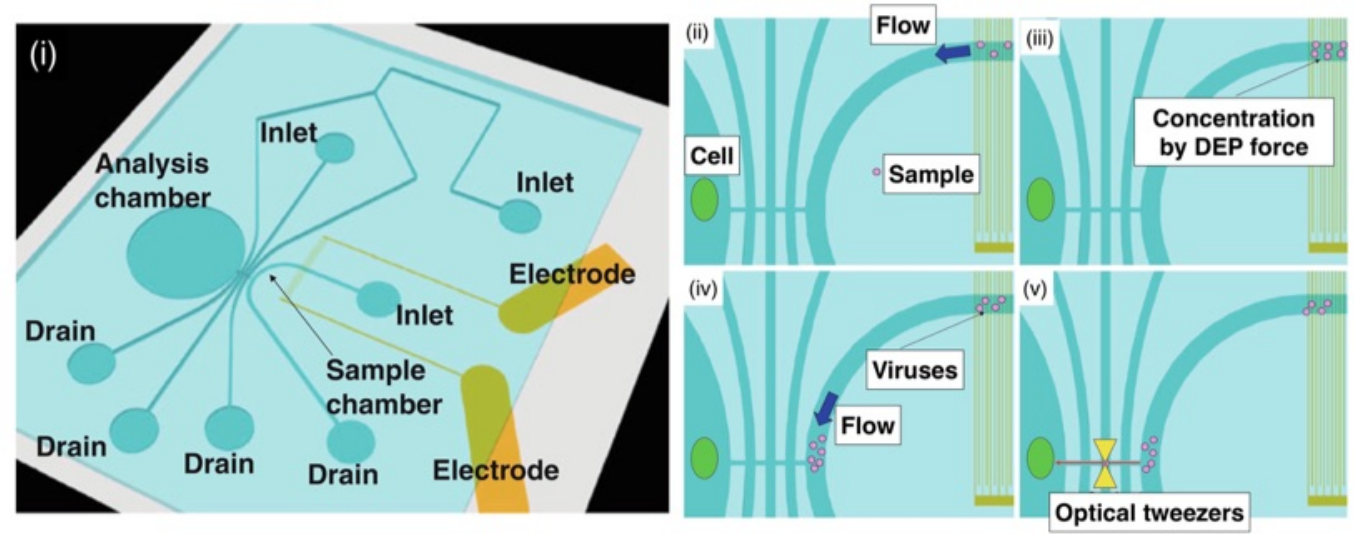

Fig. 7 Manipulation of virus. (a) DEP impedance measurement of adenovirus and rotavirus. When viruses are trapped by DEP between the electrodes, the conductance of the microelectrode is increased. Reprinted with permission from Nakano, Ding and Suehiro. ${ }^{168}$ Copyright 2016 IOP Publishing. (b) Ebola virus detection using an integrated platform. The microfluidic platform is used for sample preparation, while the optofluidic platform functions as an amplification-free detection platform. Reprinted with permission from Cai et al. ${ }^{171}$ Copyright 2015 Nature Publishing Group. (c) Influenza virus manipulation using DEP and OPT. The viruses are first concentrated by the DEP force and then flowed to the selected region. They are then delivered to the target cell by an optical tweezer. Reprinted with permission from Maruyama et al. ${ }^{169}$ Copyright 2011 Springer. 
the viruses. Adenovirus and rotavirus are viruses that cause childhood diarrhea and other clinical disease in children and adults. ${ }^{177}$

Cai et al. ${ }^{171}$ developed an Ebola virus detection platform which consists of two layers which involves a microfluidic sample preparation layer and an optofluidic detection layer (Fig. 7b). At the microfluidic layer, the viruses undergo dye-labelling by HYD configuration to their nucleic acids. At the next stage in the optofluidic layer, Ar-ion laser is used to detect the fluorescent nucleic acids. Ebola virus causes Ebola hemorrhagic with mortality rates up to $90 \% .{ }^{178,179}$

Maruyama et al. ${ }^{169}$ utilized dielectrophoresis and optical tweezing in development of manipulation platform of a single influenza virus for quantitative analysis of virus before and after infecting a cell (Fig. 7c). It uses the nDEP force to concentrate the virus at specific locations in a microfluidic system, and then OPT forces are used to transport the virus to the analysis chambers to bind the target cell. The study of influenza virus is highly important because it causes acute respiratory tract illness in children and adults in a broad range of hosts with far-reaching public health effects. ${ }^{180-183}$

Recent quantified levels of virus detection in microfluidics system has been demonstrated to within $10^{-6}$ to $10^{6}$ p.f.u. $/ \mathrm{mL}$ (Table 1). Affinity-based manipulation techniques are advantageous in the manipulation of viruses, where antigenantibody interactions are coupled to HYD ${ }^{165-167}$ or MAG ${ }^{170}$ forces. The current virus concentration limits of detection are summarized in Table 1 . These limits show high selectivity as antigen-antibody bindings are specific, however, sample preparation procedures are necessary. DEP168,169 and OPT169 forces have been utilized for manipulation of virus as mentioned. These manipulation techniques are promising tools for label-free methods, however, OPT manipulation lacks selectivity, while DEP based manipulation requires further research of suitable magnitude and frequency ranges for virus manipulation. As most virus manipulation using microfluidic platforms depend on affinity-based methods, the procedures still require for sample preparation protocols. In order to develop rapid process for virus manipulation which is free from sample preparation, exploration of non-affinity based virus manipulation microfluidic system is necessary.

\subsection{Nucleic acids}

Nucleic acids are biomolecules made from monomers known as nucleotides and they function in encoding, transmitting and expressing genetic information. ${ }^{184,185}$ There are two types of nucleic acids found in living cells, which are deoxyribonucleic acid (DNA) and ribonucleic acid (RNA). DNA is found mainly in the nucleus of the cell, and contains the genetic code to make RNA. RNA, although usually synthesized in the nucleus, is found mainly in the cytoplasm of the cell and contains codes for the primary sequence of amino acids to make proteins. ${ }^{1,186}$

Studies of nucleic acids are highly important such as for the study of replication, repair, storage and modification of DNA, ${ }^{71,72,187}$ disease biomarkers ${ }^{188}$ and gene delivery. ${ }^{189}$ Key processes in these studies which are separation and detection of nucleic acids have been demonstrated using the HYD, 190 $E P,{ }^{38}, D E P, 190 M^{19 G^{191}}$ and THM ${ }^{71}$ forces.

Ban et al. ${ }^{38}$ separated multiple micro RNAs (miRNAs) from the lung cancer line. They used capillary electrophoresis coupled with a dual laser-induced fluorescence (488 and $635 \mathrm{~nm}$ dual-laser bands) excitations to conduct simultaneous separation of hybridized miRNAs. Circulating miRNAs are small, endogenous, single-stranded, noncoding RNAs and considered as promising disease biomarkers. ${ }^{188}$

Cheng et al. ${ }^{190}$ used dielectrophoresis and shearing force to perform enhanced DNA hybridization. ${ }^{192-196}$ DNA is absorbed onto the surface of functionalized nanobeads by DEP force, while non-specifically bound DNA is removed by continuous HYD flow. Zhou et al. ${ }^{191}$ used affinity-assisted magnetophoresis to capture DNA and conduct qualitative and quantitative detection of the DNA. The assay uses magnetic microparticles (MMPs) and gold nanoparticles (Au NPs) as a sandwich type colorimetric sensor. The Au-DNA-MMPs complex and uncombined Au-NPs are separated when located in a magnetic field. The Au-DNA-MMPs complex generate color signal while uncombined Au NPs provide optical signal under ultravioletvisible spectrometry (UV-Vis) absorption spectroscopy.

$\mathrm{Yu}$ and $\mathrm{Chen}^{71}$ performed DNA detection based on affinityassisted thermophoresis using DNA-functionalized Au NPs and fluorescent DNA probes to capture target DNA in a free solution (Fig. 8a). The detection is based on change of fluorescent probes THM properties when target DNA hybridized with the probes. Study of DNA properties and reactions have also been demonstrated with different forces including the THM ${ }^{17,72}$ and OPT forces. ${ }^{81,197,198}$ Reineck, Wienken, and Braun ${ }^{17}$ studied depletion of single stranded DNA by the THM force in optical capillary and measured the Soret coefficient. Reichl and Braun 72 performed measurement of DNA binding affinities ${ }^{187}$ by manipulating molecular movement in living cells using a temperature gradient. They measured the THM mobility and intracellular diffusion coefficient across the whole cytoplasm. DNA binding is important for replication, repair, storage and modification of DNA.

Gupta et al. ${ }^{81}$ used the OPT force to study proteins and nucleic acids and how they fold into specific 3D structures. A dumble-like DNA handle between double-tweezer is constructed by double stranded DNA attached to PS beads labelled with avidin and anti-digoxigenin, respectively. The DNA handle is stretched between the double-tweezer and they measured the extension of DNA under constant force to generate the extension probability distributions and the energy-landscape profile.

Bernacka-Wojcik et al. ${ }^{197}$ used the OPT force in the development of a microfluidic platform combined with colorimetric gold nanoprobe assay for detection of single nucleotide polymorphism $(\mathrm{SNP})^{199}$ for a fat-mass and obesity-associated (FTO) gene, known as the rs993960. Characterization of SNP in FTO by Au nanoprobe is conducted by colorimetric change analysis, where light by LED is guided into the microchannel and collected back using optical fibers and air micro lens. SNP might cause a number of diseases such 
as obesity, diabetes and hypertension and also immune-related infectious diseases such as tuberculosis. ${ }^{200,201}$

Belkin et al. ${ }^{198}$ developed a DNA sequencing methodology by controlling the translocation of DNA molecules using nanoplasmonics and reading of the sequence information using SERS (Fig. 8b). DNA sequencing refers to the precise determination of nucleotides order within a DNA molecule. ${ }^{202-206}$ In this method an optical hot spot functions as an optical tweezer is used to control DNA translocational velocities. DNA translocations are generated by activation and deactivation of the plasmonic fields. The SERS scatterings from the exposed DNA fragments within the plasmonic hot spot reveal nucleotide compositions, resulting in identification of the nucleotide sequence of the DNA.

Nucleic acids introduction into the host cell has also been demonstrated using microfluidic technology, which uses the MAG force. ${ }^{207}$ Dahmani et al. ${ }^{207}$ demonstrated transfection, or introduction of nucleic acids into cells using magnetic field

(a)
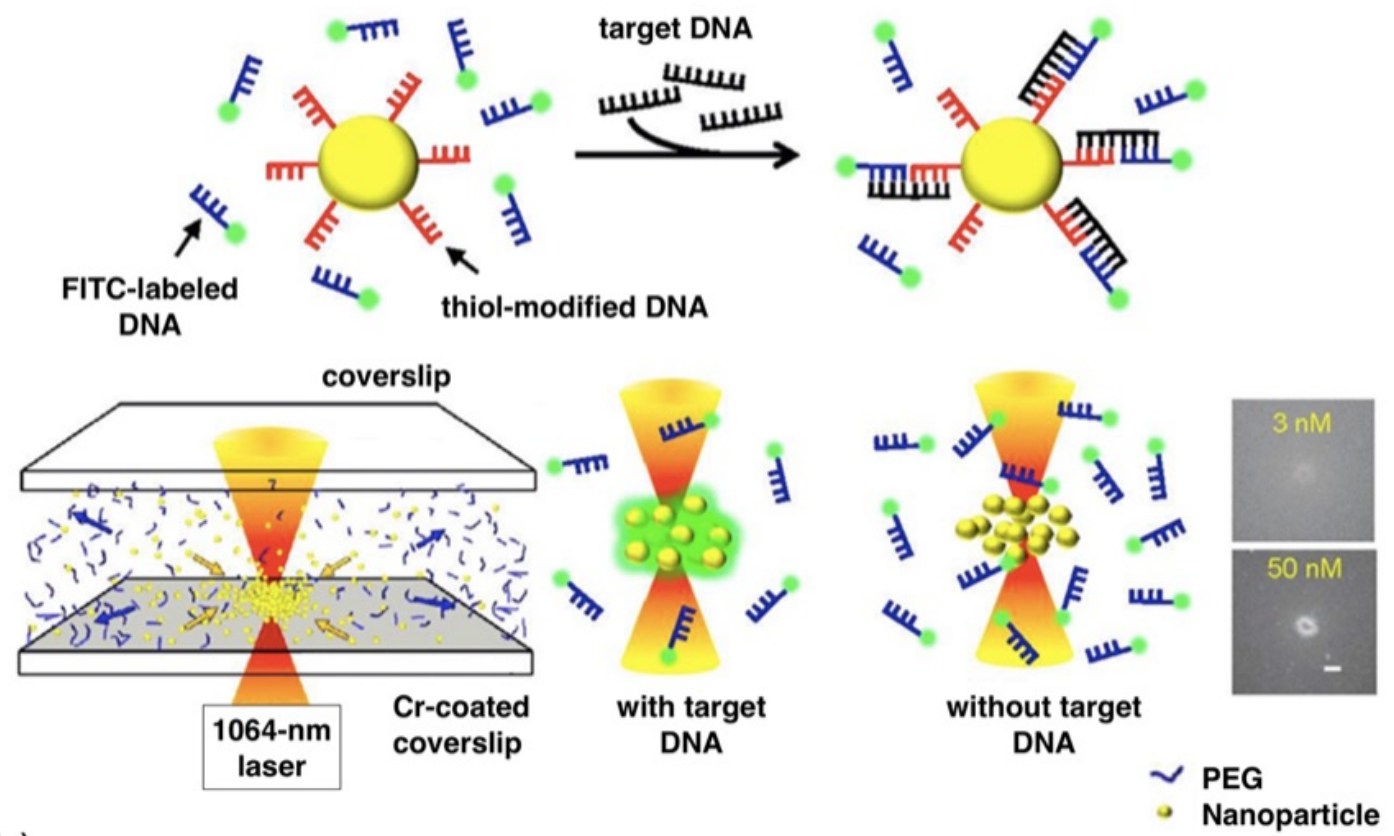

(b)

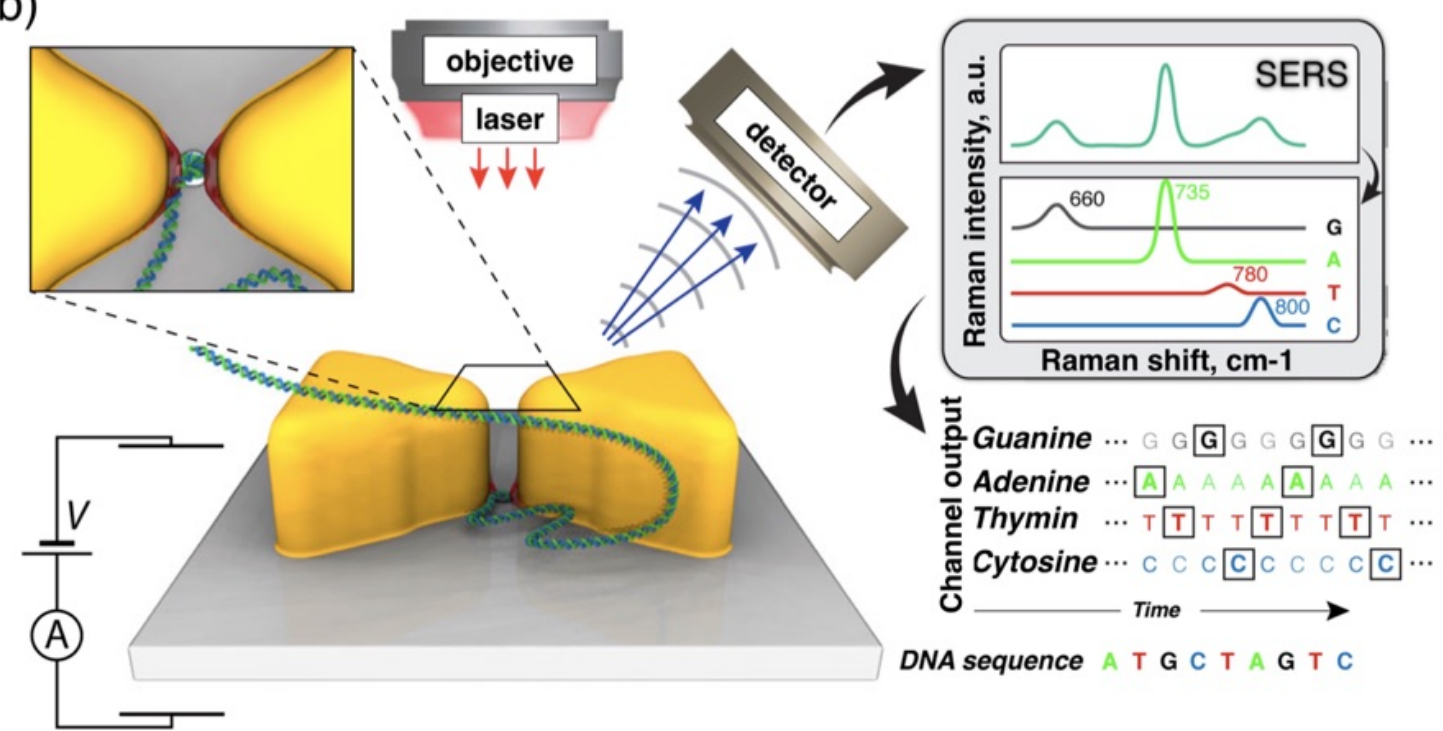

Fig. 8 Manipulation of nucleic acid. (a) Hybridized DNA spatial distribution detection using fluorescence. Fluorescein functionalized DNAs form complex with target DNAs that are attached to nanoparticles. They are then concentrated using THM forces and detected using an epi-fluorescence microscope. Reprinted with permission from Yu and Chen. ${ }^{71}$ Copyright 2015 American Chemical Society. (b) DNA translocation control using nanoplasmonics and sequence reading using SERS. Optical tweezing is used to control DNA translocational velocities within metallic nanopores located between bow tie structured gold triangular prisms. Reprinted with permission from Belkin et al. ${ }^{198}$ Copyright 2015 American Chemical Society. 
pulses. They used rotating magnets with particular frequencies and amplitudes at the location of the cells. Efficiency of transfection is enhanced by pulsed magnetofection compared to static magnetofection for both adherent and suspension cells.

THM forces show great capability in manipulation of nucleic acids, especially DNA, using DNA hybridization or affinity binding. ${ }^{17,71,72,187}$ OPT forces also exhibit high potential in controlling nucleic acids by affinity binding to biofunctionalized beads trapped using OPT forces. ${ }^{81,197,198}$ MAG forces also have the capability of introducing DNA into host cells via magnetofection using magnetic nanoparticles. DEP forces in combination with HYD forces have been used to manipulate the DNA. ${ }^{190}$ However, these methods have shown a need for biofunctionalization, which is a non-avoidable process when dealing with nucleic acid manipulation. As nucleic acids deal with genetic information, the influence of nucleic acid manipulation on cellular health, particularly mutational risks need to be studied prior to realizing a clinical application.

\subsection{Proteins}

Proteins are biomolecules consisting of a single or a number of long chains of amino acid residues. ${ }^{1}$ Protein functions within living organisms include catalyzing metabolic reactions, DNA replication, responding to stimuli and transporting molecules from one location to another. ${ }^{208}$ Proteins are different in their sequence of amino acids which originate from nucleotide sequence of their genes that specify their activity. Proteins exist for a finite period of time before it gets degraded and recycled through a protein turnover process. ${ }^{209}$ Proteins can be purified from other cellular components using a number of techniques such as ultracentrifugation, precipitation, electrophoresis and chromatography. ${ }^{210}$

Biomedical microfluidic platforms for protein manipulation have been focused on the development of tools for separation, trapping and isolation of proteins from sample for detection, quantification and sample preparation. Different forces have been utilized in the separation, trapping and isolation of proteins from the sample including the EP, ${ }^{33}$ DEP, 45,211,212 MAG, ${ }^{213-215}$ ACT ${ }^{116}$ and THM forces. ${ }^{216}$

Zhang et al. ${ }^{33}$ used electrophoresis to perform separation of the isoforms of glycosylated protein as a purification technique. The separation is based on the number of sialic acids attached to each isoform. Glycosylated protein is the protein with a carbohydrate covalently attached, which serves several functions such as improving proteins folding. ${ }^{217}$ Javanmard et al. ${ }^{45}$ used dielectrophoresis to isolate highly abundant serum proteins from cells in blood using a two-stage microfluidic platform. At the first stage, antibody conjugated beads are mixed with high abundance proteins in the blood by a hydrodynamic mixer. At second stage, cells are pushed by nDEP into a trapping trench in order to allow only serum proteins to flow out from the platform. This method can be used for low-abundance protein biomarker disease diagnostic tools such as cancer. ${ }^{218}$
Ramón-Azcón et al. ${ }^{211}$ developed a dielectrophoresis-based immuno-sensing platform for simultaneous analysis of alphafetoprotein (AFP) and prostate-specific antigen (PSA) tumor markers. Immunoreactions have been demonstrated on the surfaces of two different microparticle-antibody conjugates, including (i) PS microparticles with anti-AFP antibody conjugate and (ii) gold-coated PS microparticle with anti-PSA antibody conjugate. Both conjugates form different aggregation patterns by nDEP force, which enables simultaneous detection of AFP and PSA for tumor marker application (Fig. 9a).

Kuo and Hsieh ${ }^{212}$ used dielectrophoresis to perform a single-bead-based consecutive biochemical assay. They used fluorescein labelled streptavidin to conjugate with biotincoated $2 \mu \mathrm{m}$ PS beads and demonstrated the detection of each single fluorescein-labelled streptavidin-biotin with nDEP manipulation. Soenen et al. ${ }^{213}$ separated bound and nonbound proteins by high-gradient magnetophoresis. The separation is determined by adsorption of bovine serum albumin and egg yolk phosvitin into magnetic fluid particles by mixing with alkaline suspension of tetramethyl ammoniumcoated magnetite cores.

Hahn et al. ${ }^{214}$ used MAG forces to conduct a multiplexed immunoassay of protein. Colored microspheres are conjugated with target proteins and superparamagnetic nanoparticles (SMNPs) forming microsphere-protein-SMNP complexes. The complexes are then deflected under MAG gradient and level of deflection is determined by the degree of the conjugation with target protein (Fig. 9b).

Anandakumar et al. ${ }^{215}$ used a rotating magnetic field externally applied to conduct translocation of biofunctionalized superparamagnetic beads. The superparamagnetic beads are functionalized with streptavidin and biotin. This developed technique is highly relevant for drug delivery studies involving biomolecule carrier.

Tenje et al.116 used acoustophoresis to demonstrate isolation of plasma proteins and other low-molecular-weight compounds from RBCs in one-step process. The ACT force is used to transfer RBCs from an original plasma-containing solution into a co-flowing protein-free buffer solution in continuous flow. This method can be used for plasma protein preparation for diagnostic tools and clinical monitoring process or preparation of protein free blood for medical procedures including blood transfusion. ${ }^{219}$

Seidel et al. ${ }^{216}$ used thermophoresis with formation of local heating in a droplet induced by infrared laser. The local heating is used to concentrate adenosine $5^{\prime}$ monophosphateaptamer (AMP) locally and to quantify affinity, cooperativity and buffer of the AMP-aptamer.

Protein manipulation has been widely conducted using affinity-based methods such as protein-protein interaction and protein-DNA interaction with assistance of external manipulation force especially MAG $213-215$ and DEP. $45,211,212$ The advantage of this affinity-based method lies in the high selectivity, however, it requires sample preparation procedure. The procedure is considerably complex for laboratory studies, and undesirable for on-site work such as disease diagnostics in 
resource limited environments. Other studies have demonstrated non-affinity based methods using $\mathrm{ACT}^{116}$ forces, which is shown to be capable of manipulation in native surroundings such as blood, however, with a severe lack of selectivity. The manipulated or isolated proteins are then processed to undergo downstream analysis. THM based manipulation does not require affinity pre-processing and biofunctionalization for example in detecting changes in aptamer bound molecules. ${ }^{216}$ As protein manipulation deals with sub cell bioparticles, physical observation in microfluidic systems are rather limited. Proteins are usually indicated via biomarkers and their transformation into clinical devices is scarce due to the dependency on conventional biomarker methods. We expect that exploration of non-biomarker identification methods will provide advantages to translating these devices into clinical applications.

We have included a comparison of active bioparticle manipulation forces on each bioparticle including the processing volumes and best suited forces in Table 1 . In addition, we also provide the features and criteria of each bioparticle manipulation in Table S2 of the ESI.

(a)
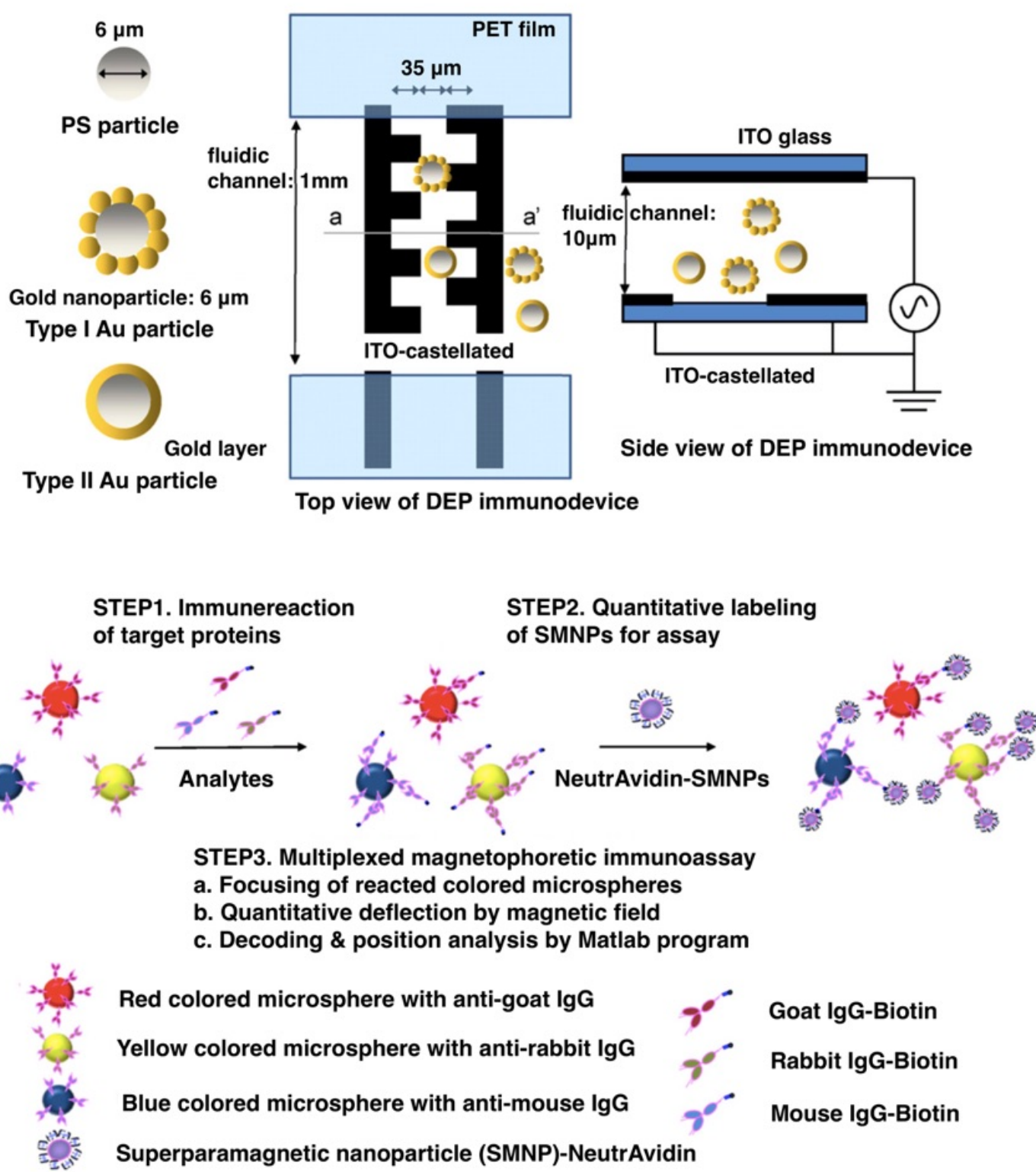

Red colored microsphere with anti-goat IgG

Yellow colored microsphere with anti-rabbit IgG

Blue colored microsphere with anti-mouse IgG

Superparamagnetic nanoparticle (SMNP)-NeutrAvidin

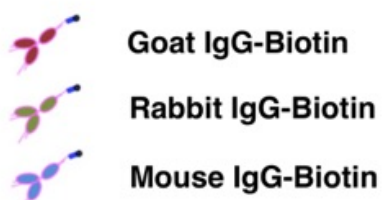

Mouse IgG-Biotin

Fig. 9 Manipulation of proteins. (a) Immuno-sensing technique for simultaneous analysis of biomarkers alpha-fetoprotein (AFP) and prostate-specific antigen (PSA). AFP and PSA demonstrate immunoreaction with different micro-particle-antibody conjugates, and later manipulated using nDEP for detection. Reprinted with permission from Ramón-Azcón et al. ${ }^{211}$ Copyright 2011 Elsevier. (b) Multiplexed immunoassay for target proteins and superparamagnetic nanoparticles (SMNPs). Target proteins first react with microspheres functionalized with antibodies by antigen-antibody reactions. Then the complexes are labelled with SMNPs. They are later detected and manipulated using magnetophoresis. Reprinted with permission from Hahn et al. ${ }^{214}$ Copyright 2009 Elsevier. 
Table 1 Processing volume, active manipulation forces and suitable control methods in microfluidics.

\begin{tabular}{|c|c|c|c|c|c|c|c|c|}
\hline Bioparticle & HYD & EP & DEP & MAG & ACT & THM & OPT & $\begin{array}{c}\text { Best- } \\
\text { suited } \\
\text { method }\end{array}$ \\
\hline $\begin{array}{c}\text { Model } \\
\text { organisms }\end{array}$ & $\begin{array}{c}\text { Ref: } 59,104-106 \\
3 \mu \mathrm{L} / \mathrm{min} \\
\text { to } \\
300 \mathrm{~mL} / \mathrm{min}\end{array}$ & & $\begin{array}{c}\text { Ref: } 46,82,84,85, \\
100 \\
100 \mathrm{~nL} / \mathrm{min} \\
\text { to } \\
50 \mu \mathrm{L} / \mathrm{min}\end{array}$ & $\begin{array}{c}\text { Ref: } 62 \\
180 \mu \mathrm{L} / \mathrm{min}\end{array}$ & $\begin{array}{c}\text { Ref: } 86 \\
10 \mathrm{~mL} / \mathrm{min}\end{array}$ & & & $\begin{array}{l}\text { HYD } \\
\text { ACT }\end{array}$ \\
\hline Blood cells & $\begin{array}{c}\text { Ref: } 58,61,87 \\
1 \mu \mathrm{L} / \mathrm{min} \\
\text { to } \\
4 \mathrm{~mL} / \mathrm{min} \\
\end{array}$ & & $\begin{array}{c}\text { Ref: } 63,89,90,119, \\
120,122 \\
70 \mathrm{~nL} / \mathrm{min} \\
\text { to } \\
15 \mu \mathrm{L} / \mathrm{min} \\
\end{array}$ & $\begin{array}{c}\text { Ref: } 63 \\
70 \mathrm{~nL} / \mathrm{min} \\
\text { to } \\
200 \mathrm{~nL} / \mathrm{min}\end{array}$ & $\begin{array}{c}\text { Ref: } 116 \\
100 \mu \mathrm{L} / \mathrm{min}\end{array}$ & & & $\begin{array}{l}\text { DEP } \\
\text { MAG }\end{array}$ \\
\hline $\begin{array}{l}\text { Tumour and } \\
\text { cancer cells }\end{array}$ & \begin{tabular}{|} 
Ref: $26,60,97,99$ \\
$80 \mu \mathrm{L} / \mathrm{min}$ \\
to \\
$7 \mathrm{~mL} / \mathrm{min}$ \\
\end{tabular} & $\begin{array}{l}\text { Ref: } 91,133 \\
2 \mathrm{~mL} / \mathrm{min}\end{array}$ & $\begin{array}{c}\text { Ref: } 47,51,92,93 \\
98 \\
4 \times 10^{-1} \text { cells } / \mathrm{mL} \\
\text { to } \\
1 \times 10^{7} \text { cells } / \mathrm{mL}\end{array}$ & 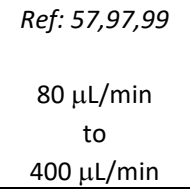 & $\begin{array}{c}\text { Ref: } 70,94,95, \\
129,135 \\
2 \mu \mathrm{L} / \mathrm{min} \\
\text { to } \\
100 \mu \mathrm{L} / \mathrm{min} \\
\end{array}$ & & $\begin{array}{c}\text { Ref: } 96 \\
1 \times 10^{6} \text { cells } / \mathrm{mL} \\
\text { to } \\
2 \times 10^{6} \text { cells } / \mathrm{mL}\end{array}$ & $\begin{array}{l}\text { DEP } \\
\text { ACT }\end{array}$ \\
\hline $\begin{array}{l}\text { Stem / } \\
\text { progenitor } \\
\text { cells }\end{array}$ & & & $\begin{array}{l}\text { Ref: } 141,142 \\
2 \mu \mathrm{L} / \mathrm{min}\end{array}$ & $\begin{array}{c}\text { Ref: } 110,143 \\
147,148,151 \\
7 \times 10^{4} \text { cells/sec }\end{array}$ & & & & MAG \\
\hline Bacteria & & $\begin{array}{c}\text { Ref: } 37 \\
4 \times 10^{7} \text { cells } / \mathrm{mL} \\
\text { to } \\
3 \times 10^{8} \text { cells } / \mathrm{mL}\end{array}$ & $\begin{array}{c}\text { Ref: } 156-158 \\
170 \mathrm{~nL} / \mathrm{min} \\
\text { to } \\
330 \mathrm{~nL} / \mathrm{min}\end{array}$ & $\begin{array}{c}\text { Ref: } 64,159 \\
150 \mu \mathrm{L} / \mathrm{min} \\
\text { to } \\
1 \mathrm{~mL} / \mathrm{min}\end{array}$ & & & $\begin{array}{c}\text { Ref: } 78 \\
1 \times 10^{5} \text { cells } / \mathrm{mL}\end{array}$ & MAG \\
\hline Viruses & $\begin{array}{c}\text { Ref: } 165-167 \\
4 \times 10^{-6} \text { p.f.u } / \mathrm{mL} \\
\text { to } \\
4 \times 10^{6} \text { p.f.u } / \mathrm{mL}\end{array}$ & & $\begin{array}{c}\text { Ref: } 168,169 \\
1 \times 10^{9} \text { viruses } / \mathrm{mL} \\
\text { to } \\
1 \times 10^{12} \text { viruses } / \mathrm{mL}\end{array}$ & $\begin{array}{l}\text { Ref: } 170 \\
10 \text { p.f.u/mL }\end{array}$ & & & $\begin{array}{c}\text { Ref: } 169,171 \\
1 \times 10^{9} \text { viruses } / \mathrm{mL} \\
\text { to } \\
1 \times 10^{12} \text { viruses } / \mathrm{mL}\end{array}$ & MAG \\
\hline Nucleic acids & $\begin{array}{c}800 \mathrm{~nL} / \mathrm{min} \\
\text { to } \\
1 \mu \mathrm{L} / \mathrm{min}\end{array}$ & $\begin{array}{c}200 \mathrm{pM} \\
\text { to } \\
10 \mathrm{nM} \\
\end{array}$ & $\begin{array}{c}800 \mathrm{~nL} / \mathrm{min} \\
\text { to } \\
1 \mu \mathrm{L} / \mathrm{min}\end{array}$ & $\begin{array}{c}\text { Ref: } 191,207 \\
100 \mathrm{pM} \\
\text { to } \\
1 \mu \mathrm{M}\end{array}$ & & $\begin{array}{c}\text { Ref: } 17,71,72, \\
187 \\
100 \mathrm{nM} \\
\text { to } \\
1 \mathrm{mM}\end{array}$ & $\begin{array}{c}\text { Ref: } 81,197,198 \\
5 \mu \mathrm{L} / \mathrm{min}\end{array}$ & $\begin{array}{l}\text { OPT } \\
\text { THM }\end{array}$ \\
\hline Proteins & & $\begin{array}{l}\text { Ref: } 33 \\
25 \mathrm{mM} \\
\text { to } \\
100 \mathrm{mM}\end{array}$ & $\begin{array}{c}\text { Ref: } 45,211,212 \\
4 \mu \mathrm{L} / \mathrm{min}\end{array}$ & $\begin{array}{c}\text { Ref: } 213-215 \\
10 \mathrm{fM} \\
\text { to } \\
30 \mathrm{fM}\end{array}$ & $\begin{array}{c}\text { Ref: } 116 \\
100 \mu \mathrm{L} / \mathrm{min}\end{array}$ & $\begin{array}{c}\text { Ref: } 216 \\
2 \mu \mathrm{M} \\
\text { to } \\
100 \mu \mathrm{M}\end{array}$ & & $\begin{array}{l}\text { MAG } \\
\text { THM }\end{array}$ \\
\hline
\end{tabular}

*p.f.u/mL: Plaque forming units (p.f.u) of virus used for infection / number of cells

\section{Conclusion and Outlook}

In this review, we critically assessed the recently developed microfluidic platforms incorporating bioparticles. These platforms utilized active bioparticle manipulation mechanisms in order to achieve particle motions, which were necessary for achieving specific biomedical processes and protocols. They also involved custom microfluidic and particle control configurations, which were found to reduce unpredictable motions when the active forces were employed. Several mechanisms and microfluidic platforms for manipulation of major bioparticles such as model organisms, blood, tumor and cancer cells, stem cells, bacteria, viruses, nucleic acids and proteins have been presented. We present our outlook for this research in the following sub-sections.
4.1 Improved understanding of bioparticle responses under multi-active forces

Future advancement of microfluidic platforms relies on detailed exploration of bioparticle properties such as permittivity and conductivity, membrane potentials, ionic permeabilities, inward directed currents due to ionic diffusions magnetic susceptibility, acoustic susceptibility, elasticity properties, thermophobicity and thermophilicity properties and optical susceptibility. ${ }^{220,221}$ Detailed theoretical and empirical understanding of these properties, mechanisms and responses of bioparticles to several active manipulation forces including HYD, EP, DEP, MAG, ACT, THM and OPT will guide the realization and improvement of bioparticles sorting, separation, assembly, enrichment, localization and isolation in desired 3D configurations of varying densities down to the 
single molecular level. These capabilities are the key features for realization of miniaturized microfluidic systems based POC therapeutics and diagnostics processes, as well as laboratory studies. ${ }^{9,222-224}$ We previously demonstrated the complex design and integration of optical laser sources into a DEP enabled micro/opto fluidic system where changes in synthetic particle configurations affected the modal propagations of light in an adjacent waveguide, enabling tuneability and reconfigurability of optical devices. ${ }^{225-229}$ Optical means have been used to identify bioparticles by means of optical interactions analysis, 225 scattering 226 and Raman spectroscopy measurements, ${ }^{230-232}$ as previously described in this review.

Comprehensive numerical models should also be developed to predict the trajectory of bioparticles when exposed to active forces. Live imaging as well as other types of microscopies, in combination with computer-enhanced image processing can be utilized to further enhance such analytical capabilities. ${ }^{106,233,234}$ Advanced numerical models will facilitate the prediction of bioparticle response under hybrid- or multiactive forces field which will optimize microfluidic morphologies.

\subsection{Development of microfluidic platforms for POC diagnosis} and clinical studies

One of the primary potential of microfluidic technology is the detection of pathogens in biological samples and environment. Future efforts are expected to focus primarily on integration of clinical experimentation steps including injection, concentration, separation, detection, and activation with full range capabilities from sample collection to analysis for realization of automated diagnostic, therapeutic and other clinical POC devices into a single compatible instrument called micro total analysis systems ( $\mu$ TAS). The purpose is for the system to be able to work with minimum requirement. ${ }^{235}$

For development of POC devices, studies and development should focus on the capability of identifying, sorting, and isolation of target bioparticles, and applying chemical and physical stimuli to change the behavior and composition of bioparticles, which enable clinical activities ranging from in vitro diagnostics to cell transplantation therapies. ${ }^{236}$ Combination of well-optimized multi parametric design of the microfluidic and controlled stimuli are required to perform the desired clinical activity in the POC platforms. ${ }^{237-239}$ Early detection of infectious diseases is critical in pandemic situations and can affect large populations. ${ }^{181}$ It leads to prevention of the pandemic spread achieved by the patient quarantine and effective therapeutic actions. Infectious diseases are caused by a wide range of bioparticles ranging from viruses, bacteria, fungi to parasites. Microfluidic platforms have been successful in detection of different pathogens, including dengue virus, ${ }^{165}$ hepatitis viruses, ${ }^{167,240}$ Ebola virus, ${ }^{171}$ (HIV), ${ }^{241}$ malaria parasites, ${ }^{87,242}$ cholera toxin, ${ }^{243}$ S. typhimurium ${ }^{158}$ and E. coli bacteria. ${ }^{156,159}$ Future research will involve advancement of microfluidic systems in disease diagnosis for high risk pandemic diseases such as tuberculosis, hepatitis, influenzas, plague and typhoid fever, using either affinity or non-affinity-based microfluidic platforms incorporating active particle manipulation.

Clinical studies covering latest developments of biomedical research such as brain and neural network studies have a great potential in biomedical platforms incorporating microfluidics. For example, advancements have been shown in neurotransmitter research involving dopamine and cathecol in microfluidics. ${ }^{244}$

Research translation of microfluidic systems into commercialized platforms are still limited as they are primarily focused on 'proof-of-concept' applications with low bioparticle throughput, lack of cellular and physiological studies and poor understanding of bioparticle behaviors. ${ }^{62,96,100,104,106,124}$ Thus, a focused research effort is necessary to address these limitations which will promote research commercialization of these platforms at a faster pace.

\subsection{Nanoproteomics and genome sequencing platform}

Genome sequencing process is used to determine the complete DNA sequence of an organism. Genome sequence of human and different infectious pathogens is very important, as it enables the genes database to be built and utilized as a solid basis for investigation and comparison in proteomics research. ${ }^{245-247}$ Proteomics research, which is the study of proteins, especially in their structures and functions, primarily aims to identify and characterize numerous biomarkers, especially for cancer and other fatal human diseases. ${ }^{248}$

Furthermore, nanomaterial research which has been growing in parallel with proteomics, has enabled a higher level of precision in the identification of post-translational protein modifications as well as to provide a more automated isolation and detection of multiple proteins in both serum and tissues. ${ }^{249,250}$ This advancement is expected to clinically aid early diagnosis and monitor disease progression, however, rapid detection of low abundance biomarkers from the complex biological samples under clinically relevant conditions is extremely difficult, and requires the development of robust, high-throughput, ultrasensitive and high-selectivity technological platform. ${ }^{251,252}$ In this regard, microfluidics is a promising technology to serve as a research and clinical platform, as it has been successfully utilized in SNP and DNA sequencing, 197,198 as well as detection, separation and purification of proteins. ${ }^{212,213}$ Low volume requirement and the possibility of integrating multiple steps and manipulation mechanisms are among the advantages of microfluidics for genomic and proteomic research. ${ }^{248,253}$

\subsection{Vaccination and drug discovery platform}

The immune system is able to tailor its specific responses for different pathogens by recognizing the infectious agents. Thus, vaccination and drug discovery with respect to the immune system is emerging and continuously developing, which can be extremely benefited from microfluidic technology. Microfluidic systems provide the ability to perform research in small volumes, contributing to the excitation of various specific medical and drug testing research globally. The major feature of this microfluidic based immune system research is the 
complex network of cells and molecules in the immune system. The mechanism of the immune system is formed by two interrelated immunities, which are known as the innate immunity and the adaptive immunity. The former is responsible for the initial response against pathogen challenges, while the latter acts as a second-line of defence including for future challenges. The adaptive immune system generates a long-lasting, antigen-specific memory $T$ and $B$ cells of WBCs by molecular recognition of receptors, which can be rapidly activated in future to clear pathogen infection. ${ }^{1}$ Microfluidic systems can provide research and clinical platforms for manipulation of antigens, molecular motif and recognition receptors, to trigger and analyze immune responses whether in innate mode or moreover adaptive mode, to suit local and global research needs. ${ }^{254-256}$

\section{5}

Research translations into commercialized biomedical breakthroughs

Recent developments in biomicrofluidic technology and bioparticle manipulation has created a strong opportunity for commercialization of biomedical research into clinical and POC devices.

The utilization of HYD forces in pregnancy test and glucometers, for example take advantage of capillary forces in the microscale regime ${ }^{257}$ and the separation of exosomes and colloids by HYD lateral displacement has achieved separation particle sizes down to the $20 \mathrm{~nm}$ scale. ${ }^{258}$ An interesting nonbiomedical HYD system has been implemented by a company known as Palo Alto Research Inc. which is capable of treating wastewater at a rate of $10 \mathrm{~L} / \mathrm{min}$, could be extended into biomedical microfluidic applications. 259

Moreover, Sandia National Laboratories has patented a method of utilizing combinations of ultrafiltration techniques with DEP separation for monitoring sources of public water supply targeting several pathogens. This method concentrates and separates bioparticles such as viruses and bacteria rapidly with volumes on the scale of $100 \mathrm{~L}$ while detecting low concentrations of microbes using sample volume reduction. ${ }^{260}$

Magnetic activated cell sorting (MACS) has been developed by a company known as Miltenyi Biotec is used for cell sorting, analysis and identification of major cells types, such as dendritic cells, endothelial progenitor cells, cancer stem cells, cytokine-secreting cells, antigen-specific $T$ cells, circulating tumor cells. ${ }^{261}$

Thermophoresis of bioparticles have been demonstrated by a company known as NanoTemper Technologies which allows investigation of interactions between molecules, ranging from ions and small molecules to high molecular and multi-protein complexes including liposomes, nanodiscs and membrane proteins. It is highly advantageous in biomedical applications due to low sample consumption down to $4 \mu \mathrm{L}$ and low concentrations at the $\mathrm{pM} / \mathrm{nM}$ scales. ${ }^{262}$

\section{Acknowledgements}

We would like to acknowledge Zahhar N. A. and Alwin G. C. W. as assistant researchers who contributed to this article. We thank the Ministry of Higher Education of Malaysia (MOHE) for support under Fundamental Research Grant Scheme (FRGS) FRGS/2/2013/TK03/UKM/01/1 and FRGS/1/2015/TK04/MMU/ $02 / 9$ and the Ministry of Education of Malaysia (MOE) for support under the Higher Institution Centre of Excellence (HiCOE) Grant, AKU-95.

\section{List of Acronyms}

Table 2 List of acronyms

\begin{tabular}{|c|c|}
\hline Acronym & Description \\
\hline$\mu \mathrm{TAS}$ & micro total analysis system \\
\hline $\mathrm{AC}$ & alternative current \\
\hline ACT & acoustophoretic \\
\hline AFP & alpha-fetoprotein \\
\hline AMP & adenosine $5^{\prime}$ monophosphate-aptamer \\
\hline Au NP & gold nanoparticle \\
\hline $\mathrm{CM}$ & Clausius-Mossotti \\
\hline СTC & circulating tumor cell \\
\hline DEP & dielectrophoretic \\
\hline DNA & deoxyribonucleic acid \\
\hline EP & electrophoresis \\
\hline EpCAM & epithelial cell adhesion molecule \\
\hline ER & electro-rotation \\
\hline FTO & fat-mass and obesity-associated \\
\hline HIV & human immunodeficiency virus \\
\hline hRBC & healthy RBC \\
\hline HYD & hydrodynamic \\
\hline IDT & interdigitated transducer \\
\hline IR & infrared \\
\hline iRBC & infected RBC \\
\hline LOC & lab-on-chip \\
\hline MAG & magnetophoretic \\
\hline miRNA & micro RNA \\
\hline MMP & magnetic microparticle \\
\hline MRI & magnetic resonance imaging \\
\hline MO & microscope objective \\
\hline NA & numerical aperture \\
\hline RBC & red blood cell \\
\hline $\mathrm{nACT}$ & negative ACT \\
\hline nDEP & negative DEP \\
\hline OPT & optical tweezing \\
\hline pACT & positive ACT \\
\hline PCR & polymerase chain reaction \\
\hline pDEP & positive DEP \\
\hline POC & point-of-care \\
\hline PS & polystyrene \\
\hline $\mathrm{RBC}$ & red blood cell \\
\hline RNA & ribonucleic acid \\
\hline SAW & surface acoustic wave \\
\hline SMNP & superparamagnetic nanoparticles \\
\hline SNP & single nucleotide polymorphism \\
\hline SSAW & standing SAW \\
\hline STR & short tandem repeat \\
\hline THM & thermophoretic \\
\hline TSAW & travelling SAW \\
\hline twDEP & travelling wave dielectrophoretic \\
\hline WBC & white blood cell \\
\hline
\end{tabular}




\section{References}

1 B. Alberts, A. Johnson, J. Lewis, M. Raff, K. Roberts, P. Walter, J. Wilson and T. Hunt, Molecular biology of the cell, Garland Science, New York, 5th edn., 2008.

2 A. I. Baba and C. Câtoi, in Comparative Oncology, The Publishing House of the Romanian Academy, Bucharest, 2007.

3 D. J. Barfoot, E. Kemp, K. Doherty, P. C. Blackburn, D. S. Sengoku, A. Van Servellen, D. A. Gavai and D. A. Karlsson, Stem Cell Research - Trends and Perspectives on the Evolving International Landscape, 2013.

4 A. A. Kayani, K. Khoshmanesh, S. A. Ward, A. Mitchell and K. Kalantar-zadeh, Biomicrofluidics, 2012, 6, 31501.

5 J. Zhou and I. Papautsky, Lab Chip, 2013, 13, 1121-1132.

6 J. M. Martel and M. Toner, Annu. Rev. Biomed. Eng., 2014, 16, 371-396.

7 K. D. Dorfman, in Encyclopedia of Microfluidics and Nanofluidics, ed. D. Li, Springer US, Boston, MA, 2008, pp. 580-588.

8 J. Voldman, Annu. Rev. Biomed. Eng., 2006, 8, 425-454.

9 H. A. Pohl, Dielectrophoresis : The behavior of neutral matter in nonuniform electric fields, Cambridge University Press, Cambridge, New York, 1978.

10 T. Z. Jubery, S. K. Srivastava and P. Dutta, Electrophoresis, 2014, 35, 691-713.

$11 \mathrm{H}$. Yan and H. Wu, in Encyclopedia of Microfluidics and Nanofluidics, ed. D. Li, Springer US, New York, 2015, pp. 1696-1701.

12 N. Pamme, J. C. T. Eijkel and A. Manz, J. Magn. Magn. Mater., 2006, 307, 237-244.

13 F. Carpino, L. R. Moore, M. Zborowski, J. J. Chalmers and P. S. Williams, J. Magn. Magn. Mater., 2005, 293, 546-552.

14 R. Yang, H. Hou, Y. Wang and L. Fu, Sensors Actuators B. Chem., 2016, 224, 1-15.

15 A. Lenshof and T. Laurell, in Encyclopedia of Nanotechnology, ed. B. Bhushan, Springer Netherlands, Dordrecht, 2015, pp. 16.

16 T. Dung Luong and N. Trung Nguyen, Micro Nanosyst., 2010, 2, 217-225.

17 P. Reineck, C. J. Wienken and D. Braun, Electrophoresis, 2010, 31, 279-286.

18 P. Baaske, C. J. Wienken, P. Reineck, S. Duhr and D. Braun, Angew. Chemie Int. Ed., 2010, 49, 2238-2241.

19 A. Ashkin, Phys. Rev. Lett., 1970, 24, 156-159.

20 M. Woerdemann, in Structured light fields : applications in optical trapping, manipulation, and organisation, Springer Berlin Heidelberg, Berlin; New York, 2012, pp. 5-26.

21 B. Çetin, M. B. Özer and M. E. Solmaz, Biochem. Eng. J., 2014, 92, 63-82.

22 H. C. Hamaker, Physica, 1937, 4, 1058-1072.

23 S. C. Glotzer, M. J. Solomon and N. A. Kotov, AlChE J., 2004, 50, 2978-2985.

24 W. B. Russel, Annu. Rev. Fluid Mech., 1981, 13, 425-455.

25 D. A. Walker, C. E. Wilmer, B. Kowalczyk, K. J. M. Bishop and B. A. Grzybowski, Nano Lett., 2010, 10, 2275-2280.

26 E. Sollier, D. E. Go, J. Che, D. R. Gossett, S. O'Byrne, W. M. Weaver, N. Kummer, M. Rettig, J. Goldman, N. Nickols, S.
McCloskey, R. P. Kulkarni and D. Di Carlo, Lab Chip, 2014, 14, 63-77.

27 I. O. Neaga, E. Bodoki, S. Hambye, B. Blankert and R. Oprean Talanta, 2016, 148, 247-256.

28 D.-M. Liu, Y.-P. Shi and J. Chen, Chinese J. Anal. Chem., 2015, 43, 775-782.

29 C. Chiappetta, M. Anile, M. Leopizzi, F. Venuta and C. Della Rocca, Clin. Chim. Acta, 2013, 425, 93-96.

30 B. Lou, E. Chen, X. Zhao, F. Qu and J. Yan, J. Chromatogr. A, 2016, 1437, 203-209.

31 J. Pieštanský, K. Maráková, M. Koval' and P. Mikuš, J. Chromatogr. A, 2014, 1358, 285-292.

32 A. Doomkaew, P. Prapatpong, S. Buranphalin, Y. Vander Heyden and L. Suntornsuk, J. Chromatogr. Sci., 2014, 53, 993999.

33 L. Zhang, K. Lawson, B. Yeung and J. Wypych, Anal. Chem., 2014, 87, 470-476.

34 J. M. Ramón-Sierra, J. C. Ruiz-Ruiz and E. de la L. OrtizVázquez, Food Chem., 2015, 183, 43-48.

35 A. Shabani, Res. J. Biotechnol., 2015, 10, 29-35.

36 Dongqing Li, Encyclopedia of microfluidics and nanofluidics, Springer, New York, 2008, vol. 1.

37 F. Oukacine, L. Garrelly, B. Romestand, D. M. Goodall, T. Zou and H. Cottet, Anal. Chem., 2011, 83, 1571-1578.

38 E. Ban, D.-K. Chae and E. J. Song, J. Chromatogr. A, 2013, 1315, 195-9.

39 K. Khoshmanesh, S. Nahavandi, S. Baratchi, A. Mitchell and K. Kalantar-zadeh, Biosens. Bioelectron., 2011, 26, 1800-1814.

40 R. Martinez-Duarte, Electrophoresis, 2012, 33, 3110-3132.

41 M. Li, W. H. Li, J. Zhang, G. Alici and W. Wen, J. Phys. D. Appl. Phys., 2014, 47, 63001

42 A. Menachery and R. Pethig, IEEE Proc. nanobiotechnology, 2005, 152, 207-211.

43 D. S. Gray, J. L. Tan, J. Voldman and C. S. Chen, Biosens. Bioelectron., 2004, 19, 771-780.

44 R. Soffe, S. Baratchi, S.-Y. Tang, M. Nasabi, P. Mclntyre, A. Mitchell and K. Khoshmanesh, Sci. Rep., 2015, 5, 11973.

45 M. Javanmard, S. Emaminejad, C. Gupta, J. Provine, R. W. Davis and R. T. Howe, Sensors Actuators, B Chem., 2014, 193, 918-924.

46 S. Van Den Driesche, V. Rao, D. Puchberger-Enengl, W. Witarski and M. J. Vellekoop, Sensors Actuators, B Chem. 2012, 170, 207-214.

47 H. J. Mulhall, F. H. Labeed, B. Kazmi, D. E. Costea, M. P. Hughes and M. P. Lewis, Anal. Bioanal. Chem., 2011, 401, 2455-2463.

48 B. Çetin and D. Li, Electrophoresis, 2011, 32, 2410-2427.

49 T. B. Jones, IEE Eng. Med. Biol. Mag., 2003, 33-42.

50 M. Muratore, S. Mitchell and M. Waterfall, Biochem. Biophys. Res. Commun., 2013, 438, 666-672.

51 F. Fabbri, S. Carloni, W. Zoli, P. Ulivi, G. Gallerani, P. Fici, E. Chiadini, A. Passardi, G. L. Frassineti, A. Ragazzini and D. Amadori, Cancer Lett., 2013, 335, 225-231.

52 F. Yu, L. Zhang, Y. Huang, K. Sun, A. E. David and V. C. Yang, Biomaterials, 2010, 31, 5842-5848.

53 B. H. McNaughton, P. Kinnunen, R. G. Smith, S. N. Pei, R. Torres-Isea, R. Kopelman and R. Clarke, J. Magn. Magn. 
Mater., 2009, 321, 1648-1652.

54 A. Lenshof and T. Laurell, Chem. Soc. Rev., 2010, 39, 12031217.

55 S. A. Peyman, E. Y. Kwan, O. Margarson, A. lles and N. Pamme J. Chromatogr. A, 2009, 1216, 9055-9062.

56 M. Getzlaff, Fundamentals of magnetism, Springer, Berlin; New York, 2008.

57 T. Schneider, L. R. Moore, Y. Jing, S. Haam, P. S. Williams, A. J. Fleischman, S. Roy, J. J. Chalmers and M. Zborowski, J. Biochem. Biophys. Methods, 2006, 68, 1-21.

58 S. Bose, R. Singh, M. Hanewich-Hollatz, C. Shen, C.-H. Lee, D. M. Dorfman, J. M. Karp and R. Karnik, Sci. Rep., 2013, 3, 2329.

59 M. E. Warkiani, A. K. P. Tay, G. Guan and J. Han, Sci. Rep., 2015, 5, 11018.

60 S. S. Kuntaegowdanahalli, A. A. S. Bhagat, G. Kumar and I. Papautsky, Lab Chip, 2009, 9, 2973-2980.

61 J. M. Martel, K. C. Smith, M. Dlamini, K. Pletcher, J. Yang, M. Karabacak, D. A. Haber, R. Kapur and M. Toner, Sci. Rep., 2015, 5, 11300.

62 J. Zeng, Y. Deng, P. Vedantam, T.-R. Tzeng and X. Xuan, J. Magn. Magn. Mater., 2013, 346, 118-123.

63 J. Jung, S. K. Seo, Y. D. Joo and K. H. Han, Sensors Actuators, B Chem., 2011, 157, 314-320.

64 P. Kinnunen, I. Sinn, B. H. McNaughton, D. W. Newton, M. A. Burns and R. Kopelman, Biosens. Bioelectron., 2011, 26, 27512755.

65 G. Destgeer, B. H. Ha, J. Park, J. H. Jung, A. Alazzam and H. J. Sung, in Physics Procedia, 2015, vol. 70, pp. 34-37.

66 L. Gao, C. Wyatt Shields, L. M. Johnson, S. W. Graves, B. B. Yellen and G. P. López, Biomicrofluidics, 2015, 9, 14105.

67 S.-C. S. Lin, X. Mao and T. J. Huang, Lab Chip, 2012, 12, 27662770.

68 M. Ohlin, I. Iranmanesh, A. E. Christakou and M. Wiklund, Lab Chip, 2015, 15, 3341-3349.

69 A. Lenshof, C. Magnusson and T. Laurell, Lab Chip, 2012, 12, 1210.

70 M. Antfolk, C. Antfolk, H. Lilja, T. Laurell and P. Augustsson, Lab Chip, 2015, 15, 2102-2109.

71 L.-H. Yu and Y.-F. Chen, Anal. Chem., 2015, 87, 2845-2851.

72 M. R. Reichl and D. Braun, J. Am. Chem. Soc., 2014, 136, 15955-15960.

73 M. Jerabek-Willemsen, T. André, R. Wanner, H. M. Roth, S. Duhr, P. Baaske, D. Breitsprecher, T. Andre, R. Wanner, H. M. Roth, S. Duhr, P. Baaske and D. Breitsprecher, J. Mol. Struct., 2014, 1077, 101-113.

74 M. A. Rahman and M. Z. Saghir, Int. J. Heat Mass Transf., 2014, 73, 693-705

75 K. K. C. Neuman and A. Nagy, Nat. Methods, 2008, 5, 491505.

76 M. Dienerowitz, L. V. Cowan, G. M. Gibson, R. Hay, M. J. Padgett and V. R. Phoenix, Curr. Microbiol., 2014, 69, 669674.

77 E. O. Eriksson, D. Engström, J. Scrimgeour and M. Goksör, Opt Express, 2009, 17, 5585-5594.

78 X. Liu, J. Huang, Y. Zhang and B. Li, Sci. Rep., 2015, 5, 11578.

79 J. P. Rickgauer and D. E. Smith, in Soft Matter

Characterization, eds. R. Borsali and R. Pecora, Springer-
Verlag, Berlin, Heidelberg, 2008, pp. 1139-1186.

80 K. Svoboda and S. M. Block, Annu. Rev. Biophys. Biomol. Struct., 1994, 23, 247-285.

81 A. N. Gupta, A. Vincent, K. Neupane, H. Yu, F. Wang and M. T. Woodside, Nat. Phys., 2011, 7, 631-634.

82 H. Zhu, X. Lin, Y. Su, H. Dong and J. Wu, Biosens. Bioelectron., 2015, 63, 371-378.

83 G. Destgeer and H. J. Sung, Lab Chip, 2015, 15, 2722-38.

84 M. D. C. Jaramillo, R. Martínez-Duarte, M. Hüttener, P. Renaud, E. Torrents and A. Juárez, Biosens. Bioelectron., 2013, 43, 297-303.

85 K. Khoshmanesh, N. Kiss, S. Nahavandi and C. W. Evans, in Proceedings of SPIE, 2011, vol. 8204.

86 J. J. Hawkes, R. W. Barber, D. R. Emerson and W. T. Coakley, Lab Chip, 2004, 4, 446-452.

87 T. Fook Kong, W. Ye, W. K. Peng, H. Wei Hou, Marcos, P. R. Preiser, N.-T. Nguyen and J. Han, Sci. Rep., 2015, 5, 11425.

88 S. Duhr, S. Arduini and D. Braun, Eur. Phys. J. E, 2004, 15, 277286.

89 M. Mohammadi, H. Madadi, J. Casals-Terré and J. Sellarès, Anal. Bioanal. Chem., 2015, 407, 4733-4744.

90 C.-C. Chen, P.-H. Lin and C.-K. Chung, Lab Chip, 2014, 14, 1996-2001.

91 Y. Deng, L. Yi, X. Lin, L. Lin, H. Li and J.-M. Lin, Talanta, 2015, 144, 136-144.

92 J. Leroy, C. Dalmay, a. Landoulsi, F. Hjeij, C. Mélin, B. Bessette, C. Bounaix Morand du Puch, S. Giraud, C. Lautrette, S. Battu, F. Lalloué, M. O. Jauberteau, a. Bessaudou, P. Blondy and a. Pothier, Sensors Actuators A Phys., 2015, 229, 172181.

93 M. B. Sano, J. L. Caldwell and R. V. Davalos, Biosens. Bioelectron., 2011, 30, 13-20.

94 C. W. Shields, L. M. Johnson, L. Gao and G. P. López, Langmuir, 2014, 30, 3923-3927.

95 X. Ding, Z. Peng, S.-C. S. Lin, M. Geri, S. Li, P. Li, Y. Chen, M. Dao, S. Suresh and T. J. Huang, Proc. Natl. Acad. Sci., 2014, 111, 12992-12997.

96 H. Zhang, E. Tu, N. D. Hagen, C. A. Schnabel, M. J. Paliotti, W. S. Hoo, P. M. Nguyen, J. R. Kohrumel, W. F. Butler, M. Chachisvillis and P. J. Marchand, Biomed. Microdevices, 2004, 38, 35-37.

97 K.-A. Hyun, T. Y. Lee, S. H. Lee and H.-I. Jung, Biosens. Bioelectron., 2015, 67, 86-92.

98 A. Salmanzadeh, L. Romero, H. Shafiee, R. C. Gallo-Villanueva, M. a. Stremler, S. D. Cramer and R. V. Davalos, Lab Chip, 2012, 12, 182-189.

99 N. M. Karabacak, P. S. Spuhler, F. Fachin, E. J. Lim, V. Pai, E. Ozkumur, J. M. Martel, N. Kojic, K. Smith, P. Chen, J. Yang, H. Hwang, B. Morgan, J. Trautwein, T. A. Barber, S. L. Stott, S. Maheswaran, R. Kapur, D. A. Haber and M. Toner, Nat. Protoc., 2014, 9, 694-710.

100 S. Burgarella, S. Merlo, B. Dell'Anna, G. Zarola and M. Bianchessi, Microelectron. Eng., 2010, 87, 2124-2133.

101 R. Rapley and J. M. Walker, Molecular biomethods handbook, Humana Press, Totowa, N.J., 1998.

102 P. Pontarotti, Evolutionary biology concept, modeling, and application, Springer, Dordrecht; New York, 2009. 
103 S. B. Hedges, Nat Rev Genet, 2002, 3, 838-849.

104 J. Akagi, K. Khoshmanesh, C. J. Hall, K. E. Crosier, P. S. Crosier, J. M. Cooper and D. Wlodkowic, Procedia Eng., 2012, 47, 8487.

105 J. Akagi, K. Khoshmanesh, C. J. Hall, J. M. Cooper, K. E. Crosier, P. S. Crosier and D. Wlodkowic, Sensors Actuators B Chem., 2013, 189, 11-20.

106 M. Cornaglia, L. Mouchiroud, A. Marette, S. Narasimhan, T. Lehnert, V. Jovaisaite, J. Auwerx and M. a. M. Gijs, Sci. Rep., 2015, 5, 10192.

107 A. V Kalueff and A. M. Stewart, Zebrafish protocols for neurobehavioral research, Humana Press, New York, 2012.

108 G. J. Tortora and B. Derrickson, Principles of anatomy and physiology, Wiley, Hoboken, N.J., 2011.

109 F. Petersson, L. Åberg, A. M. Swärd-Nilsson and T. Laurell, Anal. Chem., 2007, 79, 5117-5123.

110 Y. Jing, L. R. Moore, T. Schneider, P. S. Williams, J. J. Chalmers, S. S. Farag, B. Bolwell and M. Zborowski, Exp. Hematol., 2007, 35, 662-672.

111 H. W. Hou, A. A. S. Bhagat, W. C. Lee, S. Huang, J. Han and C. T. Lim, Micromachines, 2011, 2, 319-343.

112 N. Piacentini, G. Mernier, R. Tornay and P. Renaud, Biomicrofluidics, 2011, 5, 1-8.

113 X. Chen, D. Cui, C. Liu and H. Li, Sensors Actuators B Chem., 2008, 130, 216-221.

114 T. M. Geislinger and T. Franke, Adv. Colloid Interface Sci., 2014, 208, 161-176.

115 A. Jain and L. L. Munn, PLoS One, 2009, 4, e7104.

116 M. Tenje, M. N. Lundgren, A.-M. M. A.-M. Swärd-Nilsson, J. Kjeldsen-Kragh, L. Lyxe and A. Lenshof, Biomed. Microdevices, 2015, 17, 1-6.

117 J. Alvankarian, A. Bahadorimehr and B. Yeop Majlis, Biomicrofluidics, 2013, 7, 14102.

118 H. G. Klein and D. J. Anstee, in Mollison's Blood Transfusion in Clinical Medicine, Blackwell Science Ltd, Oxford, 11th edn., 2005, pp. 546-610.

119 S. Yan, J. Zhang, G. Alici, H. Du, Y. Zhu and W. Li, Lab Chip, 2014, 14, 2993-3003.

120 A. Sonnenberg, J. Y. Marciniak, E. A. Skowronski, S. Manouchehri, L. Rassenti, E. M. Ghia, G. F. Widhopf, T. J. Kipps and M. J. Heller, Electrophoresis, 2014, 35, 1828-1836.

121 J. McCullough, in Transfusion Medicine, Wiley-Blackwell, Oxford, 3rd edn., 2011, pp. 238-304.

122 E. Du, M. Dao and S. Suresh, Extrem. Mech. Lett., 2014, 1, 3541.

123 Z. T. F. Yu, K. M. A. Yong and J. Fu, Small, 2015, 10, 16871703.

124 N. Luciani, C. Wilhelm and F. Gazeau, Biomaterials, 2010, 31 7061-7069.

125 M. Schwab, Tumor, Springer Berlin Heidelberg, Berlin, Heidelberg, 2009.

126 R. H. Bradbury and P. Angibaud, Cancer, Springer, Berlin; New York, 2007.

127 T. N. Seyfried, Cancer as a metabolic disease on the origin, management, and prevention of cancer, John Wiley \& Sons, Hoboken, N.J., 2012

128 C. Alix-Panabières, K. Pantel and I. Lokody, Nat. Rev. Cancer,
$2014,14,623-631$.

129 P. Li, Z. Mao, Z. Peng, L. Zhou, Y. Chen, P.-H. Huang, C. I. Truica, J. J. Drabick, W. S. El-Deiry, M. Dao, S. Suresh and T. J. Huang, Proc. Natl. Acad. Sci., 2015, 112, 4970-4975.

130 M. A. Burguillos, C. Magnusson, M. Nordin, A. Lenshof, P. Augustsson, M. J. Hansson, E. Elmér, H. Lilja, P. Brundin, T. Laurell and T. Deierborg, PLoS One, 2013, 8, e64233.

131 H.-P. Deigner, EPMA J., 2014, 5, A128.

132 A.-C. Roberts, R. Barallon, S. R. Bauer, J. Butler, A. CapesDavis, W. G. Dirks, E. Elmore, M. Furtado, L. Kerrigan, M. C.Kline, A. Kohara and G. V. Los, Nat. Rev. Cancer, 2010, 10, 441-448.

133 Q. An, H. L. Fillmore, M. Vouri and G. J. Pilkington, Neuro. Oncol., 2014, 16, 265-273.

134 J. C.-I. Lee, H.-M. Hsieh, H.-F. Teng and L.-C. Tsai, in Clinical Applications of Capillary Electrophoresis: Methods and Protocols, eds. M. T. Phillips and H. Kalish, Humana Press, Totowa, NJ, 2013, pp. 113-120.

135 F. Guo, P. Li, J. B. French, Z. Mao, H. Zhao, S. Li, N. Nama and J. R. Fick, Proc. Natl. Acad. Sci., 2015, 112, 43-48.

136 R. A. Schwartz, in Skin Cancer: Recognition and Management, Blackwell Publishing Ltd, Oxford, 2nd edn., 2008, pp. 47-65.

137 S. A. Joosse, T. M. Gorges and K. Pantel, EMBO Mol. Med., 2015, 7, 1-11.

138 M. G. Krebs, J.-M. Hou, T. H. Ward, F. H. Blackhall and C. Dive, Ther. Adv. Med. Oncol., 2010, 2, 351-365.

139 D. M. Graham, M. A. Messerli and R. Pethig, Biotechniques, 2012, 52, 39-43.

140 S. Avasthi, R. N. Srivastava, A. Singh and M. Srivastava, Internet J. Med. Updat., 2008, 3, 22-30.

141 S. Y. Ng, J. Reboud, K. Y. P. Wang, K. C. Tang, L. Zhang, P. Wong, K. T. Moe, W. Shim and Y. Chen, Biosens. Bioelectron., 2010, 25, 1095-1101.

142 M. Muratore, V. Srsen, M. Waterfall, A. Downes and R. Pethig, Biomicrofluidics, 2012, 6, 34113.

143 R. J. Wilson, W. Hu, C. W. P. Fu, A. L. Koh, R. S. Gaster, C. M. Earhart, A. Fu, S. C. Heilshorn, R. Sinclair and S. X. Wang, J. Magn. Magn. Mater., 2009, 321, 1452-1458.

144 J. C. Grisar, F. Haddad, F. A. Gomari and J. C. Wu, Biomark. Med., 2011, 5, 731-44.

145 I. L. Seita, Jun; Weissman, Wiley Interdiscip Rev Syst Biol Med, 2010, 2, 640-653.

146 J. McCullough, in Supportive therapy in haematology, eds. P. C. Das, C. T. S. Sibinga and M. R. Halie, Springer US, Boston, MA, 1985, pp. 67-76.

147 C. Wilhelm, L. Bal, P. Smirnov, I. Galy-Fauroux, O. Clément, F. Gazeau and J. Emmerich, Biomaterials, 2007, 28, 3797-3806.

148 C. Rivière, C. Lecoeur, C. Wilhelm, C. Péchoux, H. Combrisson, R. Yiou and F. Gazeau, Biomaterials, 2009, 30, 6920-6928.

149 M. D. Binder, N. Hirokawa and U. Windhorst, Eds., in Encyclopedia of Neuroscience, Springer Berlin Heidelberg, Berlin, Heidelberg, 2009, p. 233.

150 P. F. Lesault, M. Theret, M. Magnan, S. Cuvellier, Y. Niu, R. K. Gherardi, J. P. Tremblay, L. Hittinger and B. Chazaud, PLoS One, 2012, 7, 1-10.

151 D. Robert, D. Fayol, C. Le Visage, G. Frasca, S. Brulé, C. Ménager, F. Gazeau, D. Letourneur and C. Wilhelm, 
Biomaterials, 2010, 31, 1586-1595.

152 B. P. Chan and K. W. Leong, Eur. Spine J., 2008, 17.

153 L. R. Hill and B. E. Kirsop, Bacteria, Cambridge University Press, Cambridge; New York, 1991.

154 E. R. Leadbetter and J. S. Poindexter, Bacteria in nature, Plenum Press, New York, 1985.

155 P. S. Bisen, M. Debnath and G. B. K. S. Prasad, Microbes concepts and applications, Wiley-Blackwell, Hoboken, N.J., 2012.

156 E. Bisceglia, M. Cubizolles, C. I. Trainito, J. Berthier, C. Pudda, O. Français, F. Mallard and B. Le Pioufle, Sensors Actuators B Chem., 2015, 212, 335-343.

157 M. Cha, J. Yoo and J. Lee, Electrochem. commun., 2011, 13, 600-604.

158 X. He, C. Hu, Q. Guo, K. Wang, Y. Li and J. Shangguan, Biosens. Bioelectron., 2013, 42, 460-466.

159 J. J. Lee, K. J. Jeong, M. Hashimoto, A. H. Kwon, A. Rwei, S. a. Shankarappa, J. H. Tsui and D. S. Kohane, Nano Lett., 2014, 14, 1-5.

160 M. T. Madigan, J. M. Martinko and J. Parker, Brock biology of microorganisms, Prentice Hall/Pearson Education, Upper Saddle River, NJ, 2003.

161 S. Baron, Medical microbiology, Univ. of Texas Medical Branch, Galveston, Texas, 1996.

162 A. W. Artenstein, Vaccines: A Biography, Springer Science+Business Media, New York, 2010, vol. 34.

163 G. P. Rédei and G. Rédel, Encyclopedia of genetics, genomics, proteomics, and informatics, Springer, New York, 2008.

164 T. Douglas and M. Young, Sci. , 2006, 312, 873-875.

165 S. Hosseini, M. M. Aeinehvand, S. M. Uddin, A. Benzina, H. A. Rothan, R. Yusof, L. H. Koole, M. J. Madou, I. Djordjevic and F. Ibrahim, Sci. Rep., 2015, 5, 16485.

166 M. M. Aeinehvand, F. Ibrahim, S. W. Harun, I. Djordjevic, S. Hosseini, H. A. Rothan, R. Yusof and M. J. Madou, Biosens. Bioelectron., 2015, 67, 424-430.

167 X. Mu, L. Zhang, S. Chang, W. Cui and Z. Zheng, Anal. Chem. 2014, 86, 5338-5344.

168 M. Nakano, Z. Ding and J. Suehiro, Jpn. J. Appl. Phys., 2016, 55, 17001.

169 H. Maruyama, K. Kotani, T. Masuda, A. Honda, T. Takahata and F. Arai, Microfluid. Nanofluidics, 2011, 10, 1109-1117.

170 W.-S. Chang, H. Shang, R. M. Perera, S.-M. Lok, D. Sedlak, R. J. Kuhn and G. U. Lee, Analyst, 2008, 133, 233-240.

171 H. Cai, J. W. Parks, T. a. Wall, M. a. Stott, a. Stambaugh, K. Alfson, a. Griffiths, R. a. Mathies, R. Carrion, J. L. Patterson, a. R. Hawkins and H. Schmidt, Sci. Rep., 2015, 5, 14494.

172 A. L. Rothman, Current Topics in Microbiology and Immunology: Dengue Virus, Springer Berlin Heidelberg Heidelberg; New York, 2010, vol. 338.

173 A. Srikiatkhachorn, A. Krautrachue, W. Ratanaprakarn, L. Wongtapradit, N. Nithipanya, S. Kalayanarooj, A. Nisalak, S. J. Thomas, R. V Gibbons, M. P. J. Mammen, D. H. Libraty, F. A. Ennis, A. L. Rothman and S. Green, Pediatr. Infect. Dis. J., 2007, 26, 283-290.

174 A. Srikiatkhachorn, Thromb. Haemost., 2009, 102, 1042-1049.

175 R. A. de Almeida Pondé, Eur. J. Clin. Microbiol. Infect. Dis., 2013, 32, 985-988.
176 D. R. Dufour, in Molecular Diagnostics: For the Clinical Laboratorian, eds. W. B. Coleman and G. J. Tsongalis, Humana Press, Totowa, NJ, 2005, pp. 461-471.

177 L. W. Lamps, Surgical pathology of the gastrointestinal system: Bacterial, fungal, viral, and parasitic infections, Springer US, New York, 2010.

178 T. G. Ksiazek, in Viral Infections of Humans: Epidemiology and Control, eds. A. R. Kaslow, R. L. Stanberry and W. J. Le Duc, Springer US, Boston, MA, 2014, pp. 337-350.

179 A. Woźniak-Kosek, J. J. Kosek, J. Mierzejewski, P. Rapiejko, D. Kurpas, B. Mroczek, J. Brodowski, M. Urban and A. NitschOsuch, Advs Exp. Med. Biol. Respir., 2015, 12, 19-24.

180 V. St. Georgiev, National Institute of Allergy and Infectious Diseases, NIH: Impact on Global Health, Humana Press, Totowa, N.J., 2009.

181 U. Reischl, Molecular diagnosis of infectious disease, Humana Press, Totowa, N.J., 1998.

182 D. Megson, G. O'Sullivan, S. Comber, P. J. Worsfold, M. C. Lohan, M. R. Edwards, W. J. Shields, C. D. Sandau and D. G. Patterson, Sci. Total Environ., 2013, 461-462, 99-107.

183 C. Sandrock, in Management of Antimicrobials in Infectious Diseases: Impact of Antibiotic Resistance, eds. G. A. Mainous III and C. Pomeroy, Humana Press, Totowa, NJ, 2010, pp. 109126.

184 S. Neidle, Principles of nucleic acid structure, Elsevier ; Academic Press, Amsterdam; Boston, 2008.

185 R. L. P. Adams, J. T. Knowler and D. P. Leader, The biochemistry of the nucleic acids, Chapman and Hall, London; New York, 1986.

186 M. X. Wang and H. Shi, in Systems Biology and Synthetic Biology, eds. P. Fu and S. Panke, John Wiley \& Sons, Inc., Hoboken, NJ, 2009, pp. 9-66.

187 S. A. I. Seidel, P. M. Dijkman, W. A. Lea, G. van den Bogaart, M. Jerabek-Willemsen, A. Lazic, J. S. Joseph, P. Srinivasan, P. Baaske, A. Simeonov, I. Katritch, F. A. Melo, J. E. Ladbury, G. Schreiber, A. Watts, D. Braun and S. Duhr, Methods, 2013, 59, 301-315.

188 N. Barron, MicroRNAs as tools in biopharmaceutical production, Springer, Dordrecht; New York, 2012.

189 M. Giacca, Gene therapy, Springer, Dordrecht; New York, 2010.

190 I. F. Cheng, H. W. Han and H. C. Chang, Biosens. Bioelectron., 2012, 33, 36-43.

191 H. Zhou, J. Kim, F. Zou, K. Koh, J. Y. Park and J. Lee, Sensors Actuators, B Chem., 2014, 198, 77-81.

192 M. Schena, DNA microarrays, Scion Publishing, Bloxham, Oxfordshire, 2008.

193 O. Y. F. Henry and C. K. O'Sullivan, TrAC Trends Anal. Chem., 2012, 33, 9-22.

194 A. J. Tavares, M. O. Noor, C. H. Vannoy, W. R. Algar and U. J. Krull, Anal. Chem., 2012, 84, 312-319.

195 L. Chen, W. R. Algar, A. J. Tavares and U. J. Krull, Anal. Bioanal. Chem., 2010, 399, 133-141.

196 F. A. Gomez, Biological applications of microfluidics, WileyInterscience, Hoboken, N.J., 2008.

197 I. Bernacka-Wojcik, H. Águas, F. F. Carlos, P. Lopes, P. J. Wojcik, M. N. Costa, B. Veigas, R. Igreja, E. Fortunato, P. V. 
Baptista and R. Martins, Biotechnol. Bioeng., 2015, 112, 12101219.

198 M. Belkin, S.-H. Chao, M. Jonsson, C. Dekker and A. Aksimentiev, ACS Nano, 2015, 9, 10598-10611.

199 S. E. Antonarakis and D. N. Cooper, in Vogel and Motulsky's Human Genetics, eds. M. R. Speicher, A. G. Motulsky and S. E. Antonarakis, Springer Berlin Heidelberg, Berlin, Heidelberg, 2010, pp. 319-363.

200 A. A. Komar, Single nucleotide polymorphisms methods and protocols, Humana Press, New York, NY, 2009.

201 Y. Feng, F. Wang, H. Pan, S. Qiu, J. Lü, L. Wu, J. Wang and C. Lu, BMC Infect. Dis., 2014, 14, 592.

202 C. A. Graham and A. J. M. Hill, DNA sequencing protocols, Humana Press, Totowa, NJ, 2001.

203 J. Wilusz, in Microbial Forensics, eds. B. Budowle, S. Schutzer, R. Breeze, P. Keim and S. Morse, Academic Press, Burlington, 2005, pp. 41-53.

204 N. V. Ravin, Appl. Biochem. Microbiol., 2010, 46, 663-670.

205 J. M. Heather and B. Chain, Genomics, 2015, 107, 1-8.

206 J. M. Terry, S. Mohr, P. R. Fielden, N. J. Goddard, N. W. Barnett, D. C. Olson, D. K. Wolcott and P. S. Francis, Anal. Bioanal. Chem., 2012, 403, 2353-2360.

207 C. Dahmani, O. Mykhaylyk, F. Helling, S. Götz, T. Weyh, H.-G. Herzog and C. Plank, J. Magn. Magn. Mater., 2013, 332, 163171.

208 D. Whitford, Proteins : structure and function, J. Wiley \& Sons, Hoboken, NJ, 2005.

209 Y. Schutz, Int. J. Vitam. Nutr. Res., 2011, 81, 2-3.

210 E. Buxbaum, in Fundamentals of Protein Structure and Function, ed. E. Buxbaum, Springer US, Boston, MA, 2007, pp. 39-51.

211 J. Ramón-Azcón, T. Yasukawa and F. Mizutani, Biosens. Bioelectron., 2011, 28, 443-449.

212 Z. T. Kuo and W. H. Hsieh, Sensors Actuators, B Chem., 2009, 141, 293-300.

213 S. J. H. Soenen, M. Hodenius, T. Schmitz-Rode and M. De Cuyper, J. Magn. Magn. Mater., 2008, 320, 634-641.

214 Y. K. Hahn, J. Chang, Z. Jin, H. Kim, J.-K. Park, Y. Ki, J. Chang, Z. Jin, H. Kim and J.-K. Park, Biosens. Bioelectron., 2009, 24, 1870-1876.

215 S. Anandakumar, V. S. Rani, S. Oh, B. L. Sinha, M. Takahashi and C. Kim, Biosens. Bioelectron., 2010, 26, 1755-1758.

216 S. A. I. Seidel, N. A. Markwardt, S. A. Lanzmich and D. Braun, Angew. Chemie Int. Ed., 2014, 53, 7948-7951.

217 R. M. Bill, L. Revers and I. B. H. Wilson, Protein glycosylation, Kluwer Academic Publishers, Boston, 1998.

218 K. Y. C. Fung, B. Tabor, M. J. Buckley, I. K. Priebe, L. Purins, C. Pompeia, G. V Brierley, T. Lockett, P. Gibbs, J. Tie, P. McMurrick, J. Moore, A. Ruszkiewicz, E. Nice, T. E. Adams, A. Burgess and L. J. Cosgrove, PLoS One, 2015, 10, 1-11.

219 J. McCullough, in Transfusion Medicine, Wiley-Blackwell, Oxford, 3rd edn., 2011, pp. 362-377.

220 S. Kalathil, M. M. Khan, J. Lee and M. H. Cho, Biotechnol. Adv., 2013, 31, 915-924.

221 R. Plonsey and R. C. Barr, Bioelectricity, Springer US, Boston, MA, 2007.

222 P. R. C. Gascoyne and J. V Vykoukal, in Proceedings Of The
IEEE, 2004, vol. 92, pp. 22-42.

223 A. Alazzam, I. Stiharu, R. Bhat and A.-N. Meguerditchian, Electrophoresis, 2011, 32, 1327-1336.

224 M. R. Buyong, J. Yunas, A. A. Hamzah, B. Y. Majlis, F. Larki and N. A. Aziz, Microelectron. Int., 2015, 32, 96-102.

225 A. A. Kayani, A. F. Chrimes, K. Khoshmanesh, V. Sivan, E. Zeller, K. Kalantar-Zadeh and A. Mitchell, Microfluid. Nanofluidics, 2011, 11, 93-104.

226 A. A. Kayani, C. Zhang, K. Khoshmanesh, J. L. Campbell, A. Mitchell and K. Kalantar-zadeh, Electrophoresis, 2010, 31, 1071-1079.

227 K. Kalantar-Zadeh, K. Khoshmanesh, A. A. Kayani, S. Nahavandi and A. Mitchell, Appl. Phys. Lett., 2010, 96, 10-12.

228 K. Khoshmanesh, C. Zhang, J. L. Campbell, A. A. Kayani, S. Nahavandi, A. Mitchell and K. Kalantar-Zadeh, Microfluid. Nanofluidics, 2010, 9, 755-763.

229 A. A. Kayani, K. Khoshmanesh, T. G. Nguyen, G. Kostovski, A. F. Chrimes, M. Nasabi, D. a. Heller, A. Mitchell and K. Kalantarzadeh, Electrophoresis, 2012, 33, 2075-2085.

230 A. F. Chrimes, K. Khoshmanesh, P. R. Stoddart, A. A. Kayani, A. Mitchell, H. Daima, V. Bansal and K. Kalantar-Zadeh, Anal. Chem., 2012, 84, 4029-4035.

231 A. F. Chrimes, P. R. Stoddart, K. Khoshmanesh, P. R. Stoddart, A. Mitchell and K. Kalantar-zadeh, Chem. Soc. Rev., 2013, 42, 5880-5906.

232 A. F. Chrimes, A. A. Kayani, K. Khoshmanesh, P. R. Stoddart, P. Mulvaney, A. Mitchell and K. Kalantar-zadeh, Lab Chip, 2011, 11, 921-928.

233 P. Yi, A. A. Kayani, A. F. Chrimes, K. Ghorbani, S. Nahavandi, K. Kalantar-zadeh and K. Khoshmanesh, Lab Chip, 2012, 12, 2520-2525.

234 M. Knoerzer, C. Szydzik, F. J. Tovar-Lopez, X. Tang, A. Mitchell and K. Khoshmanesh, Electrophoresis, 2015, 645-657.

235 M. Miró, H. M. Oliveira and M. A. Segundo, Trends Anal. Chem., 2011, 30, 153-164.

236 U. Kim, J. Qian, S. A. Kenrick, P. S. Daugherty and H. T. Soh, Anal. Chem., 2008, 80, 8656-8661.

237 D. F. Chen, H. Du and W. H. Li, Sensors Actuators A. Phys., 2007, 133, 329-334.

238 C. He, J. J. Lu, Z. Jia, W. Wang, X. Wang, P. K. Dasgupta and S. Liu, Anal. Chem., 2011, 83, 2430-2433.

239 Y. Ouyang, S. Wang, J. Li, P. S. Riehl, M. Begley and J. P. Landers, Lab Chip, 2013, 13, 1762-1771.

240 A. Kamińska, E. Witkowska, K. Winkler, I. Dzięcielewski, J. L. Weyher and J. Waluk, Biosens. Bioelectron., 2015, 66, 461467.

241 M. Glynn, D. Kirby, D. Chung, D. J. Kinahan, G. Kijanka and J. Ducrée, J. Lab. Autom. , 2014, 19, 285-296.

242 M. E. Warkiani, A. K. P. Tay, B. L. Khoo, X. Xiaofeng, J. Han and C. T. Lim, Lab Chip, 2014, 15, 1101-1109.

243 N. Bunyakul, C. Promptmas and A. J. Baeumner, Anal. Bioanal. Chem., 2014, 407, 727-736.

244 R. S. Keynton, T. J. Roussel, M. M. Crain, D. J. Jackson, D. B. Franco, J. F. Naber, K. M. Walsh and R. P. Baldwin, Anal. Chim. Acta, 2004, 507, 95-105.

245 P. D. Stenson, M. Mort, E. V. Ball, K. Shaw, A. D. Phillips and D. N. Cooper, Hum. Genet., 2014, 133, 1-9. 
Review

246 S. B. Navathe and U. Patil, in Database Systems for Advanced Applications: 9th International Conference, DASFAA 2004, Jeju Island, Korea, March 17-19, 2003. Proceedings, eds. Y. Lee, J. Li, K.-Y. Whang and D. Lee, Springer Berlin Heidelberg, Berlin, Heidelberg, 2004, pp. 1-24.

247 S. B. Navathe, U. Patil and W. Guan, J. Comput. Sci. Eng., 2007, 1, 1-30.

248 S. Ray, P. J. Reddy, S. Choudhary, D. Raghu and S. Srivastava, J. Proteomics, 2011, 74, 2660-2681.

249 R. Vaidyanathan, L. M. van Leeuwen, S. Rauf, M. J. a. Shiddiky and M. Trau, Sci. Rep., 2015, 5, 9756.

250 R. Aebersold, L. Anderson, R. Caprioli, B. Druker, L. Hartwell and R. Smith, J. Proteome Res., 2005, 4, 1104-1109.

251 M. J. A. Shiddiky, R. Vaidyanathan, S. Rauf, Z. Tay and M. Trau, Sci. Rep., 2014, 4, 3716.

252 S. M. Shameli, C. Elbuken, J. Ou, C. L. Ren and J. Pawliszyn, Electrophoresis, 2011, 32, 333-339.

253 S. Park, Y. Zhang, S. Lin, T. H. Wang and S. Yang, Biotechnol. Adv., 2011, 29, 830-839.

254 M. Look, A. Bandyopadhyay, J. S. Blum and T. M. Fahmy, Adv. Drug Deliv. Rev., 2010, 62, 378-393.

255 M. Kanapathipillai, A. Brock and D. E. Ingber, Adv. Drug Deliv. Rev., 2014, 79-80, 107-118.

256 R. D. Sochol, D. Corbett, S. Hesse, W. E. R. Krieger, K. T. Wolf, M. Kim, K. Iwai, S. Li, L. P. Lee and L. Lin, Lab Chip, 2014, 14, 1405-1409.

257 E. K. Sackmann, A. L. Fulton and D. J. Beebe, Nature, 2014, 507, 181-9.

258 B. H. Wunsch, J. T. Smith, S. M. Gifford, C. Wang, M. Brink, R. L. Bruce, R. H. Austin, G. Stolovitzky and Y. Astier, Nat. Nanotechnol, 2016, 11, 936-940.

259 Palo Alto Research Center Incorporated, https://www.parc.com/publication/2708/hydrodynamicseparation.html, accessed October 2016.

260 United States Patent, US 7811439 B1, 2010.

261 Miltenyi Biotec, https://www.miltenyibiotec.com/ /media/Files/Navigation/C ell Separation/Sorting_out_the_Facts.ashx, accessed August 2016.

262 NanoTemper Technologies, http://www.nanotempertechnologies.com/technologies/mst-technology/, accessed March 2016. 